NBER WORKING PAPER SERIES

\title{
HETEROGENEITY IN HUMAN CAPITAL INVESTMENTS: HIGH SCHOOL CURRICULUM, COLLEGE MAJOR, AND CAREERS
}

\author{
Joseph G. Altonji \\ Erica Blom \\ Costas Meghir \\ Working Paper 17985 \\ http://www.nber.org/papers/w17985
}

\author{
NATIONAL BUREAU OF ECONOMIC RESEARCH \\ 1050 Massachusetts Avenue \\ Cambridge, MA 02138 \\ April 2012
}

Forthcoming at the Annual Review of Economics doi: 10.1146/annurev-economics-080511-110908. We thank Sarah Amanda Levis for excellent research assistance and Peter Arcidiacono, Richard Murnane, Robert Triest, Seth Zimmerman and participants in a conference at the Federal Reserve Bank of Atlanta (September 2011) for helpful comments. Part of this research was conducted while Altonji was visiting the LEAP Center and the Department of Economics at Harvard University. We also received research support from Department of Economics, the Economic Growth Center, and the Cowles Foundation, Yale University. We are solely responsible for errors and omissions. The views expressed herein are those of the authors and do not necessarily reflect the views of the National Bureau of Economic Research.

NBER working papers are circulated for discussion and comment purposes. They have not been peerreviewed or been subject to the review by the NBER Board of Directors that accompanies official NBER publications.

(C) 2012 by Joseph G. Altonji, Erica Blom, and Costas Meghir. All rights reserved. Short sections of text, not to exceed two paragraphs, may be quoted without explicit permission provided that full credit, including $(\odot$ notice, is given to the source. 
Heterogeneity in Human Capital Investments: High School Curriculum, College Major, and Careers

Joseph G. Altonji, Erica Blom, and Costas Meghir

NBER Working Paper No. 17985

April 2012

JEL No. I21,J24

\begin{abstract}
Motivated by the large differences in labor market outcomes across college majors, we survey the literature on the demand for and return to high school and post-secondary education by field of study. We combine elements from several papers to provide a dynamic model of education and occupation choice that stresses the roles of specificity of human capital and uncertainty about preferences, ability, education outcomes, and labor market returns. The model implies an important distinction between the ex ante and ex post returns to education decisions. We also discuss some of the econometric difficulties in estimating the causal effects of field of study on wages in the context of a sequential choice model with learning. Finally, we review the empirical literature on choice of curriculum and the effects of high school courses and college major on labor market outcomes.
\end{abstract}

Joseph G. Altonji

Department of Economics

Yale University

Box 208264

New Haven, CT 06520-8264

and NBER

joseph.altonji@yale.edu

Erica Blom

Department of Economics

Yale University

Box 208264

New Haven, CT 06520-8264

erica.blom@yale.edu
Costas Meghir

Department of Economics

Yale University

New Haven, CT 06520-8264

c.meghir@yale.edu

An online appendix is available at:

http://www.nber.org/data-appendix/w17985 


\section{Contents}

1 Introduction

2 Lifecycle decision making: a theoretical model and some empirical implications 4

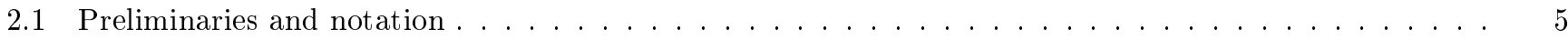

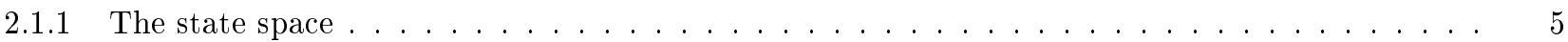

2.1.2 Updating beliefs about ability and preferences $\ldots \ldots \ldots \ldots \ldots \ldots$

2.1.3 The human capital production function $\ldots \ldots \ldots \ldots \ldots \ldots \ldots$

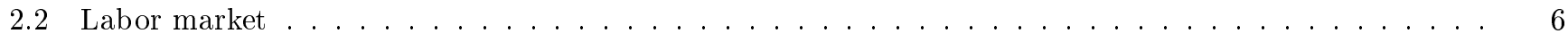

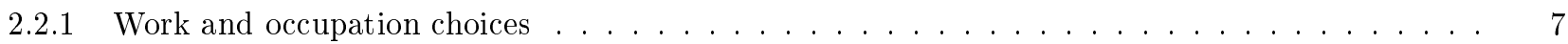

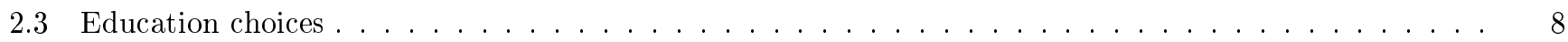

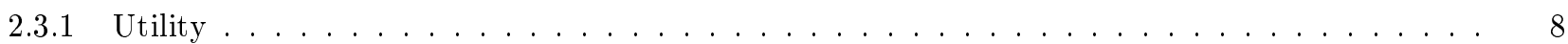

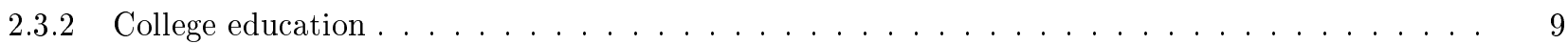

2.3 .3 High school education $\ldots \ldots \ldots \ldots \ldots \ldots \ldots \ldots \ldots$

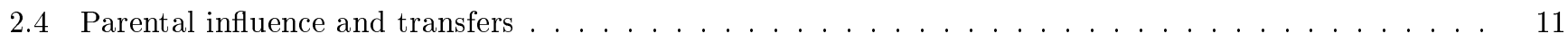

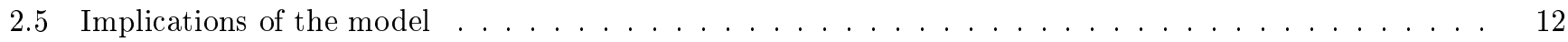

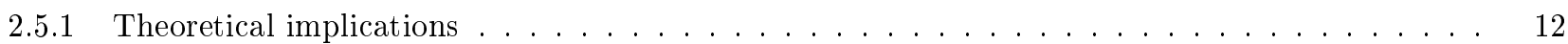

2.5.2 The returns to education paths $\ldots \ldots \ldots \ldots \ldots \ldots \ldots \ldots \ldots \ldots$

2.5 .3 Econometric implications $\ldots \ldots \ldots \ldots \ldots \ldots \ldots \ldots \ldots \ldots$

3 The effects of high school curriculum on educational attainment and wages $\quad 15$

3.1 Conclusion about the effects of high school curriculum $\ldots \ldots \ldots \ldots \ldots \ldots$

4 Empirical evidence on the determinants of college major $\quad 20$

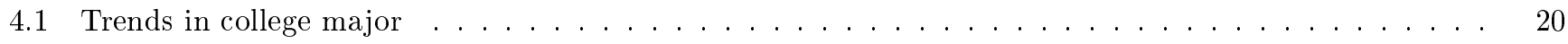

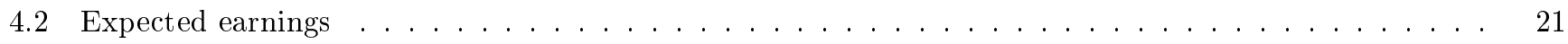

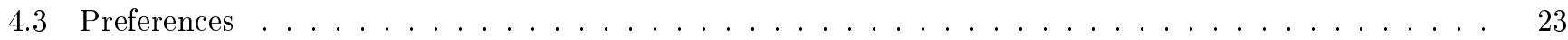

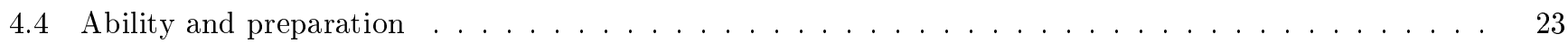

5 Returns to college major: empirical evidence $r$

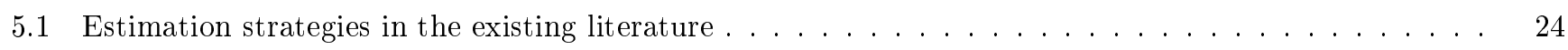

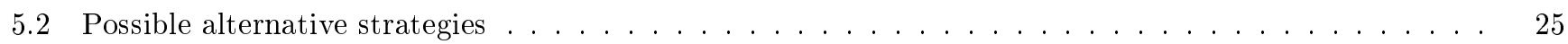

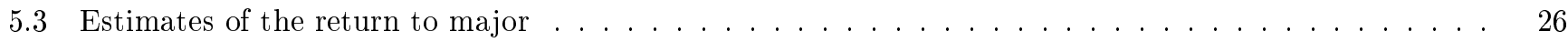

5.4 Descriptive evidence from the ACS on college major choice and returns $\ldots \ldots \ldots \ldots$

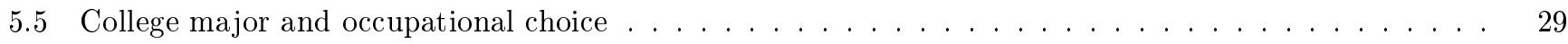

$\begin{array}{llr}6 & \text { Conclusion } & 30\end{array}$ 


\section{Introduction}

A huge literature studies educational attainment and "the return to education," with the more recent work focussing on heterogeneity in the return. ${ }^{1}$ There is much less work on why indviduals choose different types of education or on the career consequences of those choices. This is surprising, because the question of what kind of education should be provided receives an enormous amount of attention in policy discussion and is a decision that every student must make, particularly at the post-secondary level. Periodically, there are calls for reform of the high school curriculum, often in response to concern about the readiness of students for the work force. An important example is $A$ Nation at Risk (Gardner (1983)). As we discuss below, the report advocated a focus on the "new basics," with an increase in the number of courses in key academic subjects such as math and science. But despite the perennial debate about what students should study and many calls for better math and science instruction, there is surprisingly little hard evidence about the labor market consequences of specific high school courses. ${ }^{2}$

At the college level, differences by field of study have received much less attention in the academic literature than the average return to post-secondary education. This is true even though the difference in returns across college majors rivals the college wage premium. For example, using the data from the 2009 American Community Survey (ACS), we find that after adjusting for basic demographics, potential labor market experience, and graduate education, the gap in log wages rates between male electrical engineering and male general education majors is $0.561(0.016)$. This is nearly as large as the $0.577(0.003)$ difference between college graduates and high school graduates. Furthermore, the standard deviation of the return to various majors is 0.177 for men-about double the typical estimate of the value of the year of school. The President's Council of Advisors on Science and Technology (2012) is the latest in a series of policy reports calling for a major increase in college graduates in science, technology, engineering and mathematics. However, the extent to which these differences reflect unobserved differences in high school preparation and worker ability or represent compensating differentials for nonpecuniary aspects of jobs is not well-established. Understanding these differences is important for understanding the role of education in economic success and even for providing advice to students who are deciding on a course of study.

In keeping with the treatment of schooling as homogeneous, most of the literature in labor economics on career earnings focuses on the return to general experience, job tenure, and job mobility. However, there is an important and growing literature concerned with the implications of occupation-specific human capital for wages and mobility. Field of education conditions occupational paths.

In this paper, we provide a survey of the theoretical and empirical literature on the heterogeneous nature of education and its link to particular occupation paths. First, we combine elements from several papers to provide a theoretical model of education choice, occupation choice, and wages. The model has five key features. First, preferences, innate ability, and the initial vector of skills and knowledge early in high school shape the feasibility and the desirability of particular education programs. Second, individuals only learn gradually about their preferences

\footnotetext{
${ }^{1}$ See Card (1999) and Meghir and Rivkin (2011) for surveys.

${ }^{2}$ A recent example is President's Council of Advisors on Science and Technology (2011).
} 
and ability and are uncertain about wages. Third, the type of education program shapes what one learns during a schooling period. Fourth, education programs and occupations have different skill and knowledge prerequisites that influence learning and job performance. Switching fields in response to new information about ability, preferences, and returns is costly. Finally, knowledge accumulation is stochastic - students cannot simply decide that they are going to complete a program of study. We draw out a number of implications of the model that have been discussed in the literature, including an important distinction between ex ante and ex post return to an education choice. We also use the model to discuss some of the econometric difficulties that sequential choice in the presence of learning poses for estimating the causal effect of field of study on wages.

We then turn to the empirical literature on the demand for and return to particular types of education, beginning with high school curriculum and then turning to college major. We place particular emphasis on the determinants of college major and the effects of high school courses and college major on wage rates. ${ }^{3}$ We supplement the existing literature with an analysis of the returns to college major using the ACS, which is large enough for us to consider narrowly defined majors and 5-digit occupation categories. Due to space constraints, we focus primarily on the literature for the US.

We conclude with some theoretical and econometric implications of the model as well as suggestions for future research.

\section{Lifecycle decision making: a theoretical model and some empirical im- plications}

The aim of the following section is to describe a theoretical model that brings together the educational choices with the labor market careers that follow them. This sets the scene for interpreting the review of empirical results that follows. From an econometric point of view this unified framework can help identify the assumptions required for empirical analysis. As a setup, this model is not new and brings together elements of Altonji (1993) and Arcidiacono (2004), who emphasize the dynamic decisions about type of education, as well as Keane and Wolpin (1997), Eckstein and Wolpin (1989) and Violante, Gallipoli, and Meghir (2005), who also include risk considerations and examine the role of parents. We conclude this section with a discussion of the implications of the model and the important empirical challenges that this field faces. Almost all of the empirical literature we describe is either based on OLS regression or on instrumental variables strategies and focuses on specific aspects of educational choice. This work is very important, and we expect that going forward IV style approaches will continue to play a dominant role given the difficulties with structural modelling. However, the model implies that when agents are making a sequence of choices among multiple education options, the use of "single equation" methods to estimate ex ante and ex post returns to education choices requires strong assumptions. These methods also lead to incomplete measures of such returns, since costs are ignored. Readers who are primarily interested in the empirical work may wish to skip to Section 3 on a first pass through the

\footnotetext{
${ }^{3}$ We discuss the literature on the choice of high school curriculum in the supplementary appendix.
} 
paper.

We now describe the sequence of decision phases for the individual. We start from the end point where individuals make labor market decisions; we then go back through the education choices and end up at the beginning, when parents can make transfers and influence their children's decisions.

\subsection{Preliminaries and notation}

\subsubsection{The state space}

We define the state space, i.e. the set of relevant variables describing the history of events and choices made by the individual up until the current point, by $\Omega$. This includes past grades and educational attainment, and possibly past choices to the extent they have persistent effects on behavior either directly or through expectations. $\Omega_{t}$ also includes assets. Once in the labor market, $\Omega$ will track labor market history, including wages and the occupational choices that help determine the vector of skills $K$, which drives achievement in school and wages. We use the subscript $\varsigma$ to denote educational stages, i.e. high school, first part of college and second part of college. When the individual enters the labor market, we switch to a subscript $t$ which denotes years in the labor market. In general we denote labor market and education choices made in period $\tau$ by $x_{\tau}$, and other information, including grades, wages, assets, etc., by $g_{\tau}$. The state space is updated by $\Omega_{\tau}=\left\{\Omega_{\tau-1}, x_{\tau-1}, g_{\tau-1}\right\}$, where $\tau=\varsigma$ during education and $\tau=t$ during the labor market period. ${ }^{4}$ The initial information $\Omega_{I}$ will contain a vector of background variables, including parental characteristics, grades, and childhood developmental characteristics. In practice, much of the state space will be unobserved by the researcher. When implementing such a model empirically, the relevant information set would have to be suitably restricted so as to make the computational problem feasible. However, here we ignore such (important) specification issues.

\subsubsection{Updating beliefs about ability and preferences}

It is useful to think of individuals as possessing ability a (possibly multidimensional) and preferences $\theta$. Both are unknown to the individual and are a source of uncertainty. The individual learns about ability and preferences through environment and through experience, such as trying a set of courses or switching occupations in the labor market. This is helpful in explaining switches between fields of study and between occupations, as individuals learn what they can and cannot do well and what they like. We start with prior beliefs summarized by the distribution $F(a, \theta)$. These are updated according to Bayes' rule, i.e.:

$$
F^{\tau}\left(a, \theta \mid \Omega_{\tau}\right)=\propto G\left(\Omega_{\tau} \mid a, \theta\right) F^{\tau-1}\left(a, \theta \mid \Omega_{\tau-1}\right)
$$

\footnotetext{
${ }^{4}$ We make the notational distinction between the labor market periods $(t)$ and the educational periods to emphasize that they last a different amount of time. In the labor market we will think of periods as one year (or perhaps a quarter). In education we will have a high school period, a first period of college, and a second period of college, each lasting different amounts of time. It also helps distinguish the nature of the state space or choice variables.
} 
where $\tau$ denotes stage (such as high school, college, or labor market period). $G(\cdot)$ is the likelihood function of the information set $\Omega_{\tau}$. At the initial stage, which is the end of statutory schooling, $\tau-1$ is taken to be $I$, the information set is $\Omega_{I}$, and $F^{I}\left(a, \theta \mid \Omega_{I}\right)=F(a, \theta)$, i.e. the prior distribution.

In what follows, whenever ability and preferences need to be integrated out, it is done so based on the updated distribution.

\subsubsection{The human capital production function}

Productivity in the labor market and hence wages will be driven by a vector of human capital indices (skills) $K_{i t}=$ $\left\{K_{i t}^{r}\right\}, r=1, \ldots, R$, where $t$ measures time from entry in the labor market and $r$ indexes skills.

Human capital evolves as

$$
K_{i t}=f\left(K_{i t-1}, D_{i t}, a_{i}, \epsilon_{i t} \mid \Omega_{s}\right)
$$

where $\Omega_{s}$ contains the completed educational history of the individual, including choices of subjects, fields of study and majors, as well as grades. This emphasizes that accumulated skills may depend on the particular type of education followed. Skills are produced by the set of past skills and by occupational experience reflected in $D_{i t}=\left\{D_{i t}^{l}\right\}$, an $L \times 1$ vector of experiences in the $L$ possible occupations, including unemployment. Note that skills are not equivalent to occupations. However, the dependence on $D_{i t}$ reflects the fact that what one learns depends on the occupation. Before entry in the labor market, $D_{i t}$ is empty and skills are produced through education; field of study influences what one learns. $\epsilon_{i t}$ is an idiosyncratic error term that reflects the fact that knowledge accumulation is stochastic; it may depend, for example, on unforeseen illness or the quality of instructors. $f$ is increasing in $K_{i t}$ and ability, allowing possibly for self-productivity and ability-skill complementarity. Finally, the separate dependence on educational history reflects the fact that the level and type of education may lead to a permanently different type of human capital which is not perfectly substitutable with other types and which commands its own market price. For example, medical training allows one to become a surgeon, a skill not obviously substitutable with skills of individuals of a different educational background.

\subsection{Labor market}

The labor market is competitive and includes $L$ different occupations, each paying an occupation-specific wage $\alpha_{l t}$ per efficiency unit of human capital. Human capital required for the sector is a combination of the $R$ skills $K_{i t}$. It is defined by the occupational production function

$$
Q^{l}=Q^{l}(K, a)
$$

Thus the set of skills an individual $i$ accumulates defines the efficiency units she can supply in each of the sectors $l$. Assuming symmetric information between workers and employers, human capital is priced based on expectations of 
productivity from the distribution of belief about ability $F^{t}\left(a, \theta \mid \Omega_{t}\right)$. The resulting individual wage is

$$
\ln w_{i l t}=\alpha_{l t}+\ln E_{F^{t}}\left(Q_{i t}^{l}\right)+u_{i l t}
$$

where $u_{i l t}$ is an idiosyncratic shock to efficiency units for the lth occupation. In practice, one would have to find ways to restrict and refine the information set. However, this implies that factors affecting learning from individual experience will determine wages despite the fact that they have no influence on productivity itself. For example, math grades in high school may affect lawyers' wages. (See Farber and Gibbons (1996), Altonji and Pierret (2001) and Lange (2007) for work on employer learning about productivity with only general education.) Wage equations may differ for men and women, although this has not been made explicit in the above equation.

One traditional way of parametrizing the above wage equation is as follows:

$$
\ln w_{i s l t}=\alpha_{0 l t}+\alpha_{1 s l} \hat{a}_{i t}+\alpha_{2 s l} X_{i t}+\alpha_{3 s l} X_{i t}^{2}+\alpha_{4 s l} T_{i t}^{l}+v_{i l t}
$$

where $T_{i t}^{l}$ is person $i$ 's current tenure in occupation $l$ and $X_{i t}$ is total labor market experience. We use the loose notation $\hat{a}_{i t}$ to denote the expectation about ability at $t$. The subscript $s$ indicates that the coefficients of the wage equation depend on education history including the sequence of field choices and highest degree. Finally, $v_{i s l t}$ is an idiosyncratic stochastic shock. This equation is an approximation obtained by substituting out for the vector $K$ using (1), (2), and (3). Tenure in other occupations would also belong in the equation to the extent that productivity in occupation $l$ depends on skills learned in other occupations. Very recently, a few theoretical and empirical papers have appeared that formalize occupations as sets of tasks with skill requirements that overlap. ${ }^{5}$

\subsubsection{Work and occupation choices}

We now formally describe the lifecycle decision process relating to education and the labor market. It is presentationally and analytically more convenient to start from the end and move backwards, the order in which one would actually solve such a model.

Following the completion of education the individual enters the labor market and chooses between a number of different occupations, including inactivity or home production. The labor market choices are repeated in each period and the value functions are indexed by $t$, which denotes length of time in the labor market and emphasizes that this is a non-stationary lifecycle problem. The terminal condition is left unspecified here.

An individual possesses a utility function, which expresses her preference over consumption and occupations. This is denoted by $u^{l}\left(c_{t} \mid \xi_{t}^{l}, a, \theta\right)$, where $c_{t}$ is consumption and the index $l$ denotes occupation. The preference for a particular occupation is determined by a set of parameters $\theta$, by ability and by a random shock $\xi^{l}$ (with $l=B$ for unemployment). As described above, the vector $\theta$ may not be known. Beliefs about it depend on past experiences, and indeed the

\footnotetext{
${ }^{5}$ See, for example, Lazear (2009), Gathmann and Schönberg (2010), Poleatev and Robinson (2008) and Yamaguchi (2012).
} 
updating of beliefs about preferences or ability may be an important source of switching occupations. ${ }^{6}$

Now define the value of working in occupation $l$ as $V_{t}^{l}\left(\Omega_{t}, \xi_{t}^{l}\right), l=1, \ldots, L-1$ and the value of unemployment as $V_{t}^{B}\left(\Omega_{t}, \xi_{t}^{B}\right)$. We have that

$$
V_{t}^{l}\left(\Omega_{t}, \xi_{t}^{l}\right)=\max _{c, A_{t+1}}\left\{E_{a, \theta} u^{l}\left(c_{t} \mid \xi_{t}^{l}, a, \theta\right)+\beta E_{t}\left[V_{t+1}^{\mathcal{L}}\left(\Omega_{t+1}^{l}, \xi_{t+1}\right)\right]\right\}
$$

where $A_{t+1}$ are assets in period $t+1$, included in $\Omega_{t+1}^{l}\left(\Omega_{t}\right.$ includes $A_{t}$ respectively). The superscript $l$ on $\Omega_{t+1}^{l}$ indicates that each occupational choice will lead to a different point in the state space because of different labor market earnings $\left(w_{i l t}\right)$, different savings behavior $\left(A_{t+1}\right)$ and most pertinently different labor market experiences. Assets evolve based on the usual difference equation

$$
A_{t+1}=(1+r)\left(A_{t}-c_{t}+w_{i l t}\right)
$$

The expectations operator $E_{t}$ is taken with respect to information in period $t$. The value of unemployment is similarly defined, except that $w_{i l t}$ is replaced by unemployment benefits.

The optimized value of the labor market in period $t$ is then given by

$$
V_{t}^{\mathcal{L}}\left(\Omega_{t}, \xi_{t}\right)=\max _{l}\left\{\left[V_{t}^{l}\left(\Omega_{t}, \xi_{t}^{l}\right), l=1, \ldots, L-1\right], V_{t}^{B}\left(\Omega_{t}, \xi_{t}^{B}\right)\right\}
$$

This value depends on the entire set of shocks $\xi_{t}=\left\{\xi_{t}^{l}, \ldots, \xi_{t}^{L-1}, \xi_{t}^{B}\right\}$ as well as on other factors unknown in earlier periods, including shocks to wages. Thus from the perspective of earlier periods, these are sources of uncertainty, which will matter given risk aversion and incomplete insurance markets.

Important factors in practice are frictions and occupational shocks, such as exogenous job destruction. From a substantive point of view these can be important particularly if the extent of frictions differ from sector to sector. Given that individuals are risk averse, different risk characteristics may affect occupational and by implication educational choice. As we have set it up here there is still occupational risk, which is reflected in different volatility of wages.

\subsection{Education choices}

\subsubsection{Utility}

Let $j$ denote the field of study followed by the individual and $\varsigma=H, C_{1}, C_{2}$ denote the level (high school, first period of college, second period of college). The flow utility of schooling choice $(j, \varsigma)$ depends on effort exerted, on a stochastic preference shock denoted $\zeta_{\varsigma}^{j}$ and on consumption. It also depends on the individual's ability $a$ and on preferences that are known up to some person-specific vector of parameters $\theta$. Ability and preferences influence net enjoyment of pursuing $(j, \varsigma)$, including the cost of effort. We denote this utility by $u_{\varsigma}^{j}\left(c_{\varsigma} \mid \zeta_{\varsigma}^{j}, a, \theta\right)$, which does not differ notationally from the utility conditional on occupation. We often leave the school level subscript on $u$ and $c$ implicit. Since ability

\footnotetext{
${ }^{6}$ See Papageorgiou (2010) for a concise overview of the literature on learning and occupational mobility.
} 
and preferences are not known, they need to be integrated out with respect to the current distribution of beliefs and preferences $F^{\varsigma}\left(a, \theta \mid \Omega_{j \varsigma}\right)$ defined earlier.

\subsubsection{College education}

We split college into two decision periods: $C_{1}$ represents the first period of college, wherein a student can choose between a number of general courses; $C_{2}$ is a period of specialization wherein the student chooses major. $\Omega_{C_{1}}$ is the resulting information and knowledge set at the end of the first period of college, including the mix of all past courses. Grade progression is contingent on meeting certain threshold requirements, i.e. $\left(g_{C_{1}}>C_{1}^{*}\right)$, in order to continue in major $j \cdot 7$

In the second period of college, a major is chosen out of $J_{C_{2}}$ possible options, subject to having qualified. The value of a specific major $j$ is given by

$$
\begin{gathered}
V_{C_{2}}^{j}\left(\Omega_{C_{1}}, \zeta_{C_{2}}^{j}\right)= \\
\max _{c, A_{C_{2}}}\left\{E_{a, \theta} u^{j}\left(c \mid \zeta_{C_{2}}^{j}, a, \theta\right)+\beta^{C_{2}} E_{C_{2}}\left[V_{t=0}^{\mathcal{L}}\left(\Omega_{t=0}^{j}, \xi_{t=0}\right)\right]\right\}
\end{gathered}
$$

where $\zeta^{j}$ are utility shocks for major $j$ and $\xi$ is the relevant set of shocks for the labor market that will follow completion of the major. The superscript on the discount factor here and below reflects the fact that the education periods last longer than a year. Following major choice $j$ and the second period of college, the updated information set is $\Omega_{t=0}^{j}$ where, like before, the superscript $j$ denotes that the updating follows choice $j . \Omega_{t=0}^{j}$ reflects whether the student met graduation requirements for a degree in $j . A_{C_{1}}$ are assets at the point of decision and $A_{C_{2}}$ are assets at the end of the second period in college and are contained within the set $\Omega_{t=0}^{j}$. They are related by

$$
A_{C_{2}}=\left(1+r^{C_{1}}\right)\left(A_{C_{1}}-c_{2}-F_{C_{2}}^{j}\right)
$$

where $F_{C_{2}}^{j}$ represents costs of education for major $j$. Note that differential costs of education by subject matter would be very useful empirically for the purposes of identification. The function $E\left[V_{t=0}\left(\Omega_{t=0}^{j}, \xi_{t=0}\right)\right]$ is the expected value in the labor market (which starts at $t=0$ ) following major choice $j$, as defined above. The dependence on time $t$ reflects the non-stationary nature of the life-cycle problem.

Continuing with a major requires one to have satisfied the grade requirement $g_{C_{1}}>C_{1}^{*}$. Thus the value when the student has to choose one of $J_{C_{2}}$ majors is

$$
\begin{gathered}
V_{C_{2}}\left(\Omega_{C_{1}}, \zeta_{C_{2}}, \xi_{C_{2}}, g_{C_{1}}\right)= \\
\max _{j, \mathcal{L}}\left\{\left[V_{C_{2}}^{j}\left(\Omega_{C_{1}}, \zeta_{C_{2}}^{j}\right) \times 1\left(g_{C_{1}}>C_{1}^{*}\right), j=1, \ldots, J_{C_{2}}\right], V_{t=0}^{\mathcal{L}}\left(\Omega_{C_{1}}, \xi_{C_{2}}\right)\right\}
\end{gathered}
$$

\footnotetext{
${ }^{7}$ The thresholds could depend on major, but we avoid further complicating the notation.
} 
with $g_{C_{1}}$ representing the grades obtained in the first period and $C_{1}^{*}$ being the grade threshold for promotion. ${ }^{8}$ Grades are a random variable whose distribution depends on individual characteristics and effort, which we leave implicit. The choice includes the possibility of starting off in the labor market with information set $\Omega_{t=0}=\Omega_{C_{1}}$, i.e. with the educational history up until that moment, but without completing a major. This is reflected in the value function $V_{t=0}^{\mathcal{L}}\left(\Omega_{C_{1}}, \xi_{t}\right)$.

Upon finishing high school the individual chooses between college (if she qualifies) and the labor market. The information set at the beginning of that stage $\left(C_{1}\right)$ is summarized by $\Omega_{H}$. Choosing college involves choosing a particular curriculum (for example humanities versus social science versus natural sciences). This problem is presentationally similar to the one of choosing major. The value of each of the $J_{C_{1}}$ curriculum options is

$$
V_{C_{1}}^{j}\left(\Omega_{H}, \zeta_{C_{1}}^{j}\right)=\max _{c, A_{C_{1}}}\left\{E_{a, \theta} u^{j}\left(c \mid \zeta_{C_{1}}^{j}, a, \theta\right)+\beta^{C_{1}} E_{C_{1}}\left[V_{C_{2}}\left(\Omega_{C_{1}}^{j}, \zeta_{C_{2}}, \xi_{C_{2}}, g_{C_{1}}\right)\right]\right\}
$$

where $\Omega_{C_{1}}^{j}$ is the state space resulting from the $j$ th choice. Assets $A^{C_{1}}$ are given by

$$
A_{C_{1}}=\left(1+r^{H}\right)\left(A_{H}-c-F_{C_{1}}^{j}\right)
$$

where $A_{H}$ are assets following high school completion and $F_{C_{1}}^{j}$ are the monetary costs of following curriculum $j$ in the first period of college. The value at the start of the college choice period is

$$
\begin{gathered}
V_{C_{1}}\left(\Omega_{H}, \zeta_{C_{1}}, \xi_{C_{1}}, g_{H}\right)= \\
\max _{j, \mathcal{L}}\left\{\left[V_{C_{1}}^{j}\left(\Omega_{H}, \zeta_{C_{1}}^{j}\right) \times 1\left(g_{H}>H^{*}\right), j=1, \ldots, J_{C_{1}}\right], V_{t=0}^{\mathcal{L}}\left(\Omega_{H}, \xi_{C_{1}}\right)\right\}
\end{gathered}
$$

where $g_{H}>H^{*}$ signifies that the high school grades are sufficient to qualify for college.

\subsubsection{High school education}

The earliest choice the individual has to make is to attend high school and follow a particular curriculum $j, j=1, \ldots, J_{H}$. The value of choosing $j$ is

$$
V_{H}^{j}\left(\Omega_{I}, \zeta_{H}^{j}\right)=\max _{c, A_{H}}\left\{E_{a, \theta} u^{j}\left(c \mid \zeta_{H}^{j}, a, \theta\right)+\beta^{H} E_{H}\left[V_{C_{1}}\left(\Omega_{H}^{j}, \zeta_{C_{1}}, \xi_{C_{1}}, g_{H}\right)\right]\right\}
$$

where $\Omega_{I}$ represents the initial information set, including parental background and earlier school achievement, and $\Omega_{H}^{j}$ represents the updated information set given the curriculum choice $j .{ }^{9}$ High school is funded by parents. Parents also make promises of transfers that will depend on whether the child attends high school or not. These are included in

\footnotetext{
${ }^{8}$ The grades belong to the state space $\Omega_{C_{1}}$, but we make the dependence of $V_{C_{2}}$ on $g_{C_{1}}$ explicit for clarity.

${ }^{9}$ The choice that a student faces may vary across schools. School quality would influence the function as well, but we leave this implicit.
} 
$\Omega_{I}$, while at the end of this stage assets (included in $\Omega_{H}$ ) are given by

$$
A_{H}=(1+r)\left(A^{U}+w_{0}^{H}-c\right)(1-H S)+\left(1+r^{H}\right)(T-c) H S
$$

where $A^{U}$ are parental transfers if the child enters the labor market, while $T$ are transfers if the child completes high school $(H S=1)$. Any costs of school are implicit in the amount transfered. The different interest rates reflect the differences in the amounts of time for the two activities, with work lasting one year (or quarter). The resulting choice faced by the individual is between one of the possible fields of study $j$ and entering the labor market. She earns $w_{0}^{H}$ if she chooses to work at that point. The value in anticipation of this choice is

$$
V_{H}\left(\Omega_{I}, \zeta_{H}, \xi_{H}\right)=\max _{j, \mathcal{L}}\left\{\left[V_{H}^{j}\left(\Omega_{I}, \zeta_{H}^{j}\right), j=1, \ldots, J_{R}\right], V_{t=0}^{\mathcal{L}}\left(\Omega_{I}, \xi_{H}\right)\right\}
$$

The notation on the state space makes explicit that the initial position may differ depending on the parental transfers, to which we now turn.

\subsection{Parental influence and transfers}

The starting point of decision is at the end of compulsory schooling. We suppose that while the child makes her own decisions, they can be influenced by parents. Part of the influence is through genetic and cultural factors that are not the subject of conscious choices by the parent. Part is through decisions that influence the health, educational and broader social experiences of the child prior to high school. ${ }^{10}$ These are all implicit in the original information set $\Omega_{I}$, and although some may be the result of earlier choices, we do not have much to say about them here. However, one important source of influence is finance: parents choose how much to transfer to their children, either unconditionally or conditional on desired actions by the children (such as attending high school or college). This is a crucial source of funding for children who may not have other access to financial sources. From a policy perspective, understanding such transfers lies at the heart of understanding the extent to which outcomes can be influenced through government transfers.

Parents possess assets $A^{P}$. They need to choose how much to transfer to their children, given that they will fund high school and given that they may care about the child's welfare as well as whether the child completes high school. We denote by $A^{U}$ transfers offered if the child drops out of school and by $T$ transfers given if the child continues schooling. Given these, parents solve the problem

$$
\max _{T, A^{U}} E_{0}\left[V^{P}\left(A^{P}-T \times H S-A^{U} \times(1-H S), H S\right)+\kappa\left[V_{H}\left(\Omega_{I}, \zeta_{H}, \xi_{H}\right)\right]\right]
$$

subject to

$$
H S=1\left\{\max _{j}\left[V_{H}^{j}\left(\Omega_{I}, \zeta_{H}^{j}\right), j=1, \ldots, J_{R}\right]>V_{t=0}^{\mathcal{L}}\left(\Omega_{I}, \xi_{H}\right)\right\}, A^{U} \geq 0, T \geq 0
$$

\footnotetext{
${ }^{10}$ Surveys of this literature include Currie (2009), Todd and Wolpin (2003), Heckman and Masterov (2007), and many others.
} 
where $V^{P}$ is the parents' value function, $H S$ is a binary indicator for high school attendance, and $A^{U}$ and $T$ are part of $\Omega_{I}$ affecting the child's education decision. Note that we assume that transfers cannot be negative; for example, the parents cannot fine the children to induce them to attend high school. Finally, $\kappa$ is the weight attached by parents to child utility. In a standard altruistic model, transfers will increase with $A^{P}$ but will be lower for higher ability children, who can achieve higher value $V^{H}$. This is a more complicated model because of the parents' preference for their child to attend high school and their resulting willingness to use transfers to "distort" the child's choice towards education. The key point here is the link that this model creates between parental wealth and education in a world with liquidity constraints: wealthier parents will make more transfers enabling childen to study, whereas equal ability children from lower income backgrounds may be unable to do so if they cannot borrow. Conditional parental tranfers can easily be incorporated into the college stage of the model.

\subsection{Implications of the model}

\subsubsection{Theoretical implications}

The model implies an interesting interplay between preferences and the purely financial return to education. ${ }^{11}$ First, preferences and innate ability affect the ex ante financial return to completing high school, starting college, and choosing a particular major even if they play no role in the wage equation. This is because they influence the likelihood that an an individual will ultimately choose to complete a program of study and receive the ex post payoff associated with it. Second, persons with preferences for fields with high labor market payoffs, such as engineering, have higher ex ante and ex post returns to high school completion and college attendance. This is true even though preferences do not directly enter the wage equation. These two results imply, for example, that parental education and gender could affect the financial return to education even if they have no effect on wage rates. Altonji (1993) demonstrates this empirically.

Sequential decision making under uncertainty about preferences, ability, and knowledge accumulation opens up some interesting possibilities concerning the effects of wages on education outcomes. One example is that an increase in expected wages of college graduates holding the wages of high school graduates and college dropouts constant boosts the high school graduation rate and increases college enrollment but has an ambiguous effect on the college dropout rate. To see this, note first that the college wage increase will increase the ex ante return to starting college, holding constant human capital at the end of high school and beliefs about preferences and ability. On one hand, this will induce some individuals with relatively low probabilities of completing college to start, raising the college dropout rate. On the other hand, the higher payoffs will induce some individuals who would otherwise have dropped out after the first period of college to continue. A second example is that an increase in the payoff to a degree in one field, say engineering, holding the ex post payoff in other fields constant, can lead to an increase in the graduation rate in the other fields. The reason is that the increase in the engineering wage raises the ex ante return to starting college.

\footnotetext{
${ }^{11}$ See Altonji (1993) for proofs of the claims in this section using a stripped-down version of the model sketched in this section.
} 
Consequently, this higher wage will increase the number of persons who spend the first period of college in a program geared toward completing a degree in engineering by more than it reduces the number who start college in a program geared toward a humanities degree. If enough of the college entrants who start in engineering ultimately conclude that they prefer the humanities major and the occupations it leads to, and/or enough conclude that they are much more likely to be able to meet graduation requirements in humanities than in engineering, then the flow into humanities following the first period of college could be enough to offset the smaller number who start college with the intention of pursuing a humanities degree.

The role of risk aversion brings forward two important empirical issues. First, individuals will also care about uncertainty in ability and the effect of this uncertainty on alternative degrees or courses of study, possibly avoiding ones where ability might matter a lot. In general we will see a risk-return trade-off induced not only from the macroeconomic environment and the possible volatility of returns but also because of uncertainty in individual ability and microeconomic uncertainty in wages within each sector.

\subsubsection{The returns to education paths}

The model offers a systematic way of defining and measuring returns to education. Thus, for example, the returns to a major $j$ relative to dropping out of college and working is defined as

$$
R\left(\Omega_{C_{1}}, \zeta_{C_{2}}^{j}, \xi_{C_{2}}\right)=\frac{V_{C_{2}}^{j}\left(\Omega_{C_{1}}, \zeta_{C_{2}}^{j}\right)-V_{t=0}^{\mathcal{L}}\left(\Omega_{C_{1}}, \xi_{C_{2}}\right)}{V_{t=0}^{\mathcal{L}}\left(\Omega_{C_{1}}, \xi_{C_{2}}\right)}
$$

This depends on individual heterogeneity, known to the individual but not to the econometrician. The estimated return will be an average of this function and will depend on individual history. Thus, we can document how the returns differ across individuals with different choice history of courses, grades, etc. The ex ante heterogeneity of returns is driven partly by these differences in early experiences and partly by the way that they affect individual perceptions and expectations of their ability and preferences. Moreover, they take fully into account the costs of education, including opportunity cost and effort involved in alternative course choices.

\subsubsection{Econometric implications}

The model we presented also brings to the fore econometric issues that will appear when reviewing the literature. First, wages across different levels of education and fields of study are best described by a Roy-type model, implying heterogeneous returns to education. In other words this is a switching regressions framework (see Quandt (1972), Heckman and Robb (1985)). Ex post the selection into any of the sectors will be endogenous to the extent that preferences about education are correlated with unobserved determinants of wages (lazy at school and lazy at work for example) and to the extent that information about future wages is known by the individual at the time education choices are made, but is unobserved by the econometrician. For example, if an individual knows they will be more productive working in an office rather than outdoors, this will influence the sequence of education choices and imply 
that education choice is endogenous for wages, even if education and labor market ability are themselves independent.

This brings us to the difficult question of identifiability and identification in practice. The model highlights the costs of education as the main source of exogenous variation: a low-cost college can trigger a chain of decisions that leads to college completion, where this may have not happened if fees were higher. Thus if there is variation in the costs of obtaining alternative combinations of education, and if such variation can be taken as exogenous (i.e. not correlated with quality of education or with the characteristics of the individuals having access to such fees), this can be an important source of exogenous variation. However, as shown in Heckman and Navarro (2007) and further discussed in Meghir and Rivkin (2010), this may be far from enough to identify such dynamic models non-parametrically. Thus, in practice, identification will be in part driven by such exogneous variables and by restrictions on the functional forms of the distribution of unobservables.

The dynamic model presents a clear approach to estimating both an education choice model and the returns to education, as well as the specific properties of wages. Any source of endogeneity is taken into account and there is transparency regarding the assumptions made. However, it is a complicated model; to include all the detail we have suggested may be almost impossible in practice. Thus, a dynamic approach will have to impose a number of simplifications and will rely on functional form restrictions. The complexity of such models and the detailed data requirements can be a serious impediment to their use.

Meanwhile, most of the literature we review has taken the simpler approach of estimating relatively simple wage equations based on instrumental variables. The cost is the limited external validity and alternative assumptions that in a sense take the place of the ones required by the ful dynamic structural model: Imbens and Angrist (1994) have shown that IV will identify the Local Average Treatment Effect parameter (LATE), which is the effect of the binary treatment on those who were induced into treatment (college in our example) by the variation in the value of the instrument. If the instrument (say reform assignment) is independent of all the unobservables, such is the case when it is randomized, then LATE identifies the effect of those who switched into treatment as a result of the reform under the key additional assumption that no one is induced out of treatment as a result of the policy (monotonicity). In this case the theoretical framework can be suggestive of whether monotonicity is valid.

With many different treatments, as would arise in our context of multiple levels of education and curriculum choices, it is harder to interpret instrumental variables, even if we had enough instruments. This of course does not mean that the dynamic model is necessarily our only alternative. Consider, for example, the wage equation, and take expectations conditional on a set of instruments that have been randomized $(Z)$ and on educational history denoted by $S$. Assume that the dimension $l$ indexes the education path. (We will ignore for this example the labor market history as well as time in the labor market.)

$$
E\left[\ln w_{i l} \mid S_{i}=S_{i}^{l}, Z=z_{i}\right]=\alpha_{l t}+\beta_{s^{l}} S_{i}^{l}+E\left(u_{i l} \mid S_{i}=S_{i}^{l}, Z=z_{i}\right)
$$

This is a standard Roy model and its identifiability has been studied by Heckman and Honore (1990). $\beta_{s^{l}}$ is the 
average ex post return to education path $S_{i}^{l}$. In terms of our notation the issue is whether the control function assumption required, i.e. that $E\left(u_{i l} \mid S_{i}=S_{i}^{l}, Z=z_{i}\right)=E\left(u_{i l} \mid S_{i}=S_{i}^{l}\right)$ and whether it has independent variation from

the education choices $S_{i}^{l}$. The form of this function is driven by the dynamic selection process described earlier in the theoretical model. Constructing this control function will require a model for $S$. In general this is not going to be a single index model, because of the sequential nature of the choices; hence the need for many instruments. For example, Cameron and Heckman (1998) have shown that education choice can be represented by an ordered choice model (which hugely simplifies the identification and estimation problem) when there is just one unobserved factor driving educational decisions. When we depart from this very framework, we will need more than one index to represent the choice of $S_{i}$ as well as many instruments. This is an issue of both sufficient amounts of exogenous variation and the correct structure. In interpreting the results of the existing empirical literature, we need to remember that important identification questions remain both when implementing the full dynamic structure and when estimating a simpler version of the model. But given the complexity and pitfalls of estimation based on dynamic structural models, we expect careful studies using IV strategies or OLS with rich controls to continue to play a critical role in the literature going forward.

\section{The effects of high school curriculum on educational attainment and wages}

As we noted in the introduction, there is surprisingly little hard evidence about the causal effects of specific high school courses on educational attainment and labor market outcomes. ${ }^{12}$ This is partly due to data limitations, but mostly due to the fact that student course selection is not random given the available options, as is clear from the model in Section 2. Furthermore, student curriculum choices are shaped by school requirements, tracking policy, and guidance, and these reflect to some extent the qualifications and interests of the student body. In the supplemental appendix, we provide a brief discussion of trends in course taking, socieconomic correlates of course taking and role of graduation requirements, but we found little model-based curriculum choice. The complexity of the subject is undoubtedly part of the reason why. Even with excellent data, identifying the causal effects of high school courses on educational attainment, choice of college major and occupation, and wage rates is a difficult task.

In this section we review the limited evidence on the effects of high school curriculum. We emphasize wage effects but also touch upon educational attainment and choice of major. We discuss the approaches to estimation that are used and briefly summarize the results. None of the studies we reviewed model the endogeneity of curriculum choice by allowing for dynamics. The implication is a lack of clarity of the underlying determinants of both wages and educational choice, as we discussed in Section 2. The existing empirical studies estimate equations of the form

$$
S_{i}=C_{i} G_{s}+X_{i} B_{s}+C_{i} g_{s i}+e_{s i}
$$

\footnotetext{
${ }^{12}$ Due to space constraints, we do not discuss evidence on the effects of curriculum on test scores.
} 
for educational attainment $S$ and

$$
\ln \text { Wage }_{i}=C_{i} G_{w}+X_{i} B_{w}+\rho S_{i}+C_{i} g_{w i}+e_{w i}
$$

for wages where here $C_{i}$ denotes high school curriculum, $X_{i}$ denotes background and other characteristics, $e_{w i}$ and $e_{s i}$ are unobserved random intercepts, and $g_{s i}$ and $g_{w i}$ are unobserved random coefficients. $C_{i}$ is typically a count of the number of year-long courses taken in various subjects. It is likely to be correlated with the composite error terms in the equations, which will lead to bias in OLS estimates of $G_{s}$ and $G_{w}$. Studies differ in a number of ways including in the assumed exogenous source of variation for the curriculum, in whether or not all courses are examined at the same time rather than one by one or in subsets, in whether courses in a given subject area are differentiated by level, and in whether the analysis is conditional on high school graduation.

An important issue is whether one should control for post-secondary education $S$ in the wage equation. Doing so affects the interpretation of the coefficient on $C$. The entire history and type of educational attainment will affect wages to the extent that each path leads to a different set of skills. As specified in (5), $G_{w}$ is the average effect of courses on lnWage holding years of post secondary education constant. For example, high school math and science courses may influence the types of jobs obtained by students who enter the workforce after high school or facilitate completion of a BS in engineering as opposed to a lower-paying college major. Controlling for post-secondary education in some fashion makes sense because post-secondary schooling is costly. However, if the return $\rho$ exceeds the interest rate, then part of the return to $C_{i h}$ is through facilitating profitable investments in $S$. It raises the option value of investment in $S$. Altonji (1995) reports a set of estimates based on including $S$ in the wage equation with $\rho$ set to 0.04 , which he assumes is the real discount rate. Most studies report estimates with and without $S$. None of the papers that estimate $\rho$ addresses the fact that $S$ is endogenous in (5).

We now to turn to the studies. Altonji (1995) is the first comprehensive study of the effects of curriculum on postsecondary educational attainment and wages. ${ }^{13}$ He uses data from the National Longitudinal Study of 1972 (NLS72), which follows samples of 12 th grade students from a large number of high schools. His specification of (4) and (5) includes counts of courses in eight subject areas: math, science, English, social studies, foreign languages, commercial studies, industrial arts and fine arts. His main identification strategy uses the substantial amount of variation across high schools in the average value $C_{h}$ of $C_{i}$ as an instrumental variable for $C_{i}$, where $h$ is the high school $i$ attends. ${ }^{14}$ If the variation in $C_{h}$ reflects high school or school district policies that are unrelated to the distribution of aptitude, ability, and prior preparation of the student body, then use of high school averages as excluded instruments would yield consistent estimates of the average treatment effect of an extra semester of math, science, etc. But casual observation, as well as the evidence from the NLS72 and other similar data sets, indicates that variation across schools in the quantity of academic courses is positively related to both the level and quality of the courses and to the quality

\footnotetext{
${ }^{13}$ Rumberger and Daymont (1984) is a noteworthy early study of the effects of curriculum on wages shortly after high school.

${ }^{14}$ For example, Table 1 of his paper reports that cross-school variation accounts for $25.9 \%, 26.9 \%$ and $26.4 \%$ of the variation across students in science, foreign language, and math, respectively.
} 
of the students. These associations would imply a positive bias in $G_{w}$ and $G_{s}$, because course quality and level is not accounted for and the controls for family background, primary school preparation, and high school quality are imperfect.

Altonji's IV estimates indicate that the effects of additional courses in academic subjects are small. Even when controls for family background and ability are excluded, the combined effect of an extra year of science, math, foreign language, English, and social studies is only 0.3 percent - far less than the value of a year of high school. The combined effect of an extra year of science, math, foreign language is only $0.017(0.012)$ when family background controls for the student and the school are included. The point estimate for math is actually negative, $-0.007(0.015)$, although one cannot rule out a substantial positive effect given the standard error. The IV estimates indicate that students who do not go to college benefit from vocational courses.

Altonji also reports OLS estimates with family background controls. These are somewhat larger than the IV estimates, but nevertheless also suggest that the value of additional courses is too small to account for the value of a year of high school. ${ }^{15}$ The conclusion is not very sensitive to how post-secondary education is treated, in part because the courses have only have a modest effect on post-secondary education. Altonji's conclusion is not that courses have little effect, but rather that the results, which are not easy to dismiss with an appeal to unobserved heterogeneity, pose a challenge for researchers. He raises the possibility that the estimates for particular courses are affected by the interaction of biases in the coefficients on the curriculum variables and/or the control variables.

Levine and Zimmerman (1995) use a framework and methods similar to Altonji's. However, they use different data sets (NLSY79 and High School and Beyond (HS\&B)), focus on math and science classes, stress differences by gender, and look at a broader set of outcomes. They rely primarily upon OLS because their estimates using cross high school variation in course taking are noisy. Controlling for post-secondary education, their OLS estimates suggest that a year of math raises the wage by between 0.028 and $0.056 \mathrm{log}$ points for men and about 0.044 for women. The point estimates vary within education group and are largest for female college graduates. The estimates of the effects of science are mixed in sign and not statistically significant.

Levine and Zimmerman find that both math and science courses boost educational attainment. There is evidence that additional math and science courses increase the probability of choosing a technical college major. This evidence relates directly to the question of how the type of education one chooses at the high school level conditions the optimal choice of education and occupation later. Additional math and science courses move women toward jobs that involve more mathematical reasoning, although the evidence is stronger in HS\&B than in NLSY79.

As the authors emphasize, the OLS estimates may be biased upward by selection in course-taking and the other issues discussed in more detail in Altonji (1995). Nevertheless, the findings of the positive effect of math and the evidence pointing to an effect of math and science on the probability that the individual majors in a technical field are interesting.

\footnotetext{
${ }^{15}$ This is true even through the coefficients of separate OLS regressions relating the log wage to a year of science, foreign language, and math with no controls are very large: $0.054,0.040$, and 0.072 , respectively.
} 
Rose and Betts (2004) use the 1982 senior cohort from HS\&B to provide a more nuanced study of the return to high school math. Their primary dependent variable is log earnings in 1991. They control for demographic characteristics and family background variables in most of their analysis, include high school dropouts, and control for highest degree. Their main innovation is to take advantage of detailed transcript information and differentiate math courses by levelvocational math, pre-algebra, algebra/geometry, intermediate algebra, advanced algebra, and calculus. They find that a year of math substantially raises wage rates even when math GPA and math test scores are controlled for. The returns are larger for advanced math courses, particularly algebra and geometry. They obtain positive estimates using OLS and using an IV approach based on cross-school variation, although the OLS estimates are stronger, perhaps in part because they are more precise.

The math results are robust to including English, science, and foreign language. English courses enter positively, and the OLS estimate suggests the return of $0.026(0.013)$ to a semester of upper-level English, while the IV estimate is 0.071 (0.036). The coefficients on science courses are negative for lower-level courses and positive but not significant for upper-level physics, chemistry, and AP biology. The OLS estimates indicate that a student who takes a year of calculus, English, chemistry, and foreign language would earn about $8.6 \%$ more than a 12 th grade student who did not take any courses. Consequently, Rose and Betts come closer than Altonji in accounting for the value of a year of high school. On the other hand, the return to a year of low-level courses in the 11th grade and in the 12th grade is small. Rose and Betts attempt to reconcile their OLS and IV results with Altonji's smaller estimates. They conclude that the difference stems from their disaggregation by course level in case of IV and disaggregation by course level and their use of math GPA rather than test scores as a control in the case of OLS. On the other hand, Rose and Betts' IV estimates are large and negative for several of the advanced math courses. Some of the differences between the two studies may reflect sampling error. Furthermore, concerns remain about positive selection in who is taking advanced courses. But overall, the study significantly advances our understanding of the payoff to different types of courses.

Joensen and Neilson (2008) estimate the return to advanced high school math by exploiting an educational reform in Denmark in 1988 which allowed students to combine advanced math with chemistry rather than only with physics. The reform was piloted at some high schools during the years 1984 through 1987. These reforms were plausibly exogenous for students who chose their school before the pilot was introduced. The authors find that taking the advanced math course in combination with the advanced chemistry course increases earnings by $0.20 \log$ points. The estimate rises to 0.25 when they exclude schools that are able to unilaterally decide whether to implement the pilot program because there is evidence of negative selection for that group. Interestingly, the OLS estimate is similar (0.23) when detailed controls are included, as is the IV estimate based on the cross high school means $C_{h}$. There is not much evidence of selection bias. ${ }^{16}$ Controlling for post-secondary educational attainment eliminates most of the effect, in contrast to the US studies.

In interpreting their estimates, Joensen and Neilson make the monotonicity assumption that students who had

${ }^{16}$ The OLS results are weighted toward students who took math in combination with advanced physics because the advanced math and chemistry combination was only available in the pilot schools. Consequently, the OLS and IV estimators identify different parameters. 
chosen advanced math when only the advanced math and physics combination was available would continue to take an advanced math package following the introduction of the advanced math-chemistry option. This is reasonable, but even if this assumption is true, their estimator does not have a LATE interpretation as the effect of advanced math. This is because their IV strategy precludes controlling for whether the student took math in combination with physics or math in combination with chemistry. Some of the students who were induced to choose the advanced math and chemistry combination would have chosen a curriculum involving less math, while some would have chosen advanced math with advanced physics. Despite this ambiguity in the interpretation of the results, this study is a valuable contribution that illustrates the potential for research that exploits sharp curriculum reforms.

Goodman (2009) exploits curriculum reforms inspired by A Nation at Risk (1983). In the years following the report, a number of states established course requirements in core academic subjects or increased existing ones. Goodman's instrument is the indicator MathReform for whether students in a given high school class from a given state were subject to an increased math requirement relative to what prevailed for the high school class of 1982 . Because the state laws are not very powerful instruments, a large sample could help in improving precision if the within state error correlation is limited. Goodman employs a Two Sample Instrumental Variables (TSIV) estimator that uses micro data sets on student high school transcripts to estimate the first stage and wage and educational outcome data from the 2000 Decennial Census to estimate the second stage. Controlling for state and high school cohort, MathReform is associated with an increase of about 0.184 years of basic math and 0.214 years of advanced math for black males. The impact for black females is somewhat smaller, and the impact for white males and females is about half as large and is concentrated in basic math. The corresponding TSIV estimates of the effect of a year of math are -0.030 (0.048) for white females and about 0.08 for the other three groups. About $40 \%$ of this effect is due to an increase in educational attainment. ${ }^{17}$ When education policy controls, economic controls, and census division level trends are added, the TSIV estimates become 0.052 (0.018), 0.035 (0.030), 0.033 (0.030) and 0.005 (0.041) respectively. The effects tend to be larger for disadvantaged groups, but one should not make too much of the differences given the sampling errors. It should also be kept in mind that the specification does not include controls for other courses. (The reform instruments are not powerful enough to identify the effects of different courses.)

\subsection{Conclusion about the effects of high school curriculum}

Some progress has been made toward the goal of providing hard evidence on the effects of high school curriculum on wages and educational attainment. Breaking out courses by level, as in the Rose and Betts study, indicates that taking more advanced courses has a substantial economic return. While there are clear concerns about selection bias, their result is reinforced by Joensen and Neilson's clever IV study, although it is worrisome that most of their large effect of taking advanced math and chemistry is through post-secondary education independent of the field of post-secondary

\footnotetext{
${ }^{17}$ We arrived at the $40 \%$ figure based on the fact that the reduced form coefficients relating log earnings to MathReform fall from 0.028 to 0.019 (0.008) for black males, 0.026 to 0.016 (0.008) for black females, and 0.020 to 0.011 (0.010) for white males when education/graduating class interactions are added to the baseline specification. The estimates are negative but not significant for white females regardless of whether education is in the model.
} 
education. These results, along with Goodman's TSIV estimates and Levine and Zimmerman's results, suggest that additional math courses have substantial value. There is also some evidence that vocational courses have value for students who did not intend to go to college. (See, for example, Altonji (1995) and Mane (1999) and additional references that she provides.) However, there is still considerable uncertainty about the value of particular courses of study, about how the courses affect post-secondary education, and about heterogeneity in these effects.

We have two suggestions for research. The first is to make use of the huge student record data sets that have become available in several US states and other countries. This information, combined with post-secondary education records and earnings (as is possible, for example, for the states of Florida and Texas) and in conjunction with information about specific reforms to curriculum at the high school and/or school district level, provides a way to address the problem of endogeneity of curriculum. A panel data set on course graduation requirements and course availability will have to be assembled for a large set of schools. Furthermore, the student record data sets can be used to study how curriculum affects post-secondary field, which has been difficult to do because of sample size considerations in the panel data sets discussed above. The second is to integrate the study of curriculum choice into a dynamic model of educational attainment and labor market outcomes, along with sources of exogenous of variation in curriculum. This would help elucidate how courses are chosen and how education choices today influence future opportunities. Furthermore, it will provide a systematic way of addressing selection in course-taking in a dynamic setting when estimating the return to curriculum.

\section{Empirical evidence on the determinants of college major}

The theoretical framework presented above implies that college major choice is influenced by expectations of future earnings, preferences, ability, and preparation. We discuss some of the evidence on the role of each of these factors, drawing on both the small number of structural models and on the more extensive reduced-form approaches. First, however, we document some trends.

\subsection{Trends in college major}

Patterns of college major choice have been relatively steady over the past twenty years. Supplementary Figure 1 illustrates the trends across college graduation cohorts in the fractions of degrees accounted for by the five most popular aggregated college majors. The results are shown separately for men and women. ${ }^{18}$ In keeping with the high school course-taking trends, the fraction of science majors has shown a slight uptick in recent years. Taking a longer view, the fraction of education majors has decreased substantially over the past forty years, while the proportion of business and economics majors peaked about twenty-five years ago, following a period of rapid growth in the 1980s.

\footnotetext{
${ }^{18}$ Data are from the 2009 ACS; respondents are assumed to graduate at age 22. Supplementary Figure 2 reports trends from 1984 to 2009 based on data from the Integrated Postsecondary Education System (IPEDS). There are some minor differences that could be due to recall bias in ACS, changes in IPEDS coverage, the fact that the ACS includes immigrants who received degrees abroad and IPEDS includes degrees of foreign students who later return home, the fact that some individuals obtain more than one bachelors degree, and differences in aggregation of majors.
} 
Later in this section we estimate the contribution of this change in composition to the growth of the college wage premium in the 1980 s.

Not surprisingly, women are far more prevalent in education, and men in engineering and in business and economics. However, this figure disguises interesting within-category trends. While women have caught up with men in the sciences overall, Turner \& Bowen (1999) point out that the disaggregated trends show a surge of women in biology, for example, but not in the more mathematical sciences. Similarly, the oft-used "social sciences" category includes majors as dissimilar as economics and cultural studies. To address this, Figure 1 reports the trends over time in the fraction female in selected majors relative to the fraction female across all majors. The trends in the relative fractions are not affected by the rise in the share of women among all college graduates or changes in the general popularity of particular majors. Remarkably, although the relative fraction of women in most science-related majors has increased over time, the relative fraction female among computer science majors has actually dropped. ${ }^{19}$

Table 1 describes various characteristics associated with some of the more common college majors: share enrolled, fraction female, math and science course content, SAT scores, wages, and the share attending graduate school. ${ }^{20}$ There is a great deal of variation across majors: engineers have among the highest SAT math scores, for example, while elementary education majors have among the lowest. Similarly, wages tend to be high for engineers and low for elementary education majors, suggesting that perhaps much of the wage differences between majors are due to differences in mathematical ability and high school course work.

The table also reports the 10th and 90th percentiles of the hourly wage distribution. The size of the gap relative to the mean varies substantially across majors. For example, mean earnings in economics is about 10 percent higher than in mechanical engineering, but the 90-10 differential is twice as large. Part of the variation in the 90th percentile reflects differences across fields in the contribution of graduate school, but the basic pattern is present for those who do not go to graduate school. ${ }^{21}$

\subsection{Expected earnings}

The work on the impact of expected earnings on major choice uses three main approaches. The first uses a rational expectations-type framework in which expected future earnings are based upon a statistical model of earnings. Berger (1988) is an early example of this. He models the utility from major $j$ as the consumption value of the major plus the present value of expected lifetime earnings in major $j$. In doing so he improves upon previous myopic models that incorporate only first-year post-college earnings. The coefficient on expected earnings in the conditional logit model has the expected positive sign.

However, Berger's model does not account for uncertainty about preferences, ability, or academic progress. Changes in these factors will lead some students to leave school or change fields, as emphasized in the theoretical section. In

\footnotetext{
${ }^{19}$ See Goldin et al (2006) for an excellent overview of long-run trends in the educational attainment and high school curriculum and college major choices of women.

${ }^{20}$ The wage and share data are from the ACS, and the other data are from the 1993/2003 Baccalaureate \& Beyond survey.

${ }^{21}$ For example, among individuals without graduate degrees the mean, 10th percentile and 90th percentile values are 43.7, 14.3 , and 80.6 for economics and 41.2, 20.1, and 61.9 for mechanical engineering. See Supplementary Table 2.
} 
Altonji's (1993) model, uncertainty regarding ability and preferences leads to probabilistic major completion even if ex post monetary payoffs are known. He emphasizes the distinction between the ex ante and ex post return to a particular course of study. (Note that the estimates in the next section are all ex post returns; that is, returns contingent on completion of a major.) The ex ante return is the return associated with starting a particular major, and includes the possibility of dropping out entirely, switching majors, or proceeding on to a graduate degree. Altonji does not estimate his theoretical model, but Arcidiacono's (2004) econometric model has some of the same features. ${ }^{22}$ Montmarquette et al (2002) break down expected (ex ante) returns into the probability of completing a major, and earnings contingent on completing a major. They find that expected earnings (the product of the two) has more predictive power than either on its own.

While many papers include the expected wages associated with a terminal college degree in the choice equation, Eide \& Waehrer (1998) also incorporate the option value of graduate school. For both men and women the option value of graduate school increases the likelihood of majoring in science or liberal arts relative to business, although the magnitudes differ significantly by gender.

A few recent papers directly measure expectations. They use specialized surveys (usually confined to one school) to assess students' subjective expectations about wages. A more representative sample of colleges would be preferable, but these studies provide unique insights into college students' decision-making.

Betts (1996) finds that University of California-San Diego seniors are much better informed about wages than freshmen, suggesting that students may wait to learn about their abilities and preferences before investing in informationgathering. This has implications for the timing and informativeness of information shocks about the labor market in our model, relative to the preference and learning shocks $\zeta$ and $\epsilon$. Given the difficulty of majoring in science and engineering if one does not lay the foundation in freshman and sophomore year, students may be obtaining the labor market information after it is too late. Betts also shows that students from lower-income families systematically underestimate earnings for college-educated workers.

Arcidiacono, Hotz \& Kang (2010) find that major choice is based on comparative advantage, in that Duke sophomores expect to have higher earnings in the major in which they are currently enrolled than in other majors (with the exception of economics, which all students believe would lead to higher earnings). Students also tend to be more accurate about future earnings in their own major than in other majors. Zafar (2009b) (Northwestern sophomores) and Betts (1996) find similar results. Reassuringly, students' earnings expectations do correlate with actual earnings.

The literature on choice of major also considers risk aversion. With concave preferences, students should consider

\footnotetext{
${ }^{22}$ Altonji estimates probit models for the probability of 19 post-secondary education outcomes as a function of demographic characteristics, family background, high school curriculum, and a vector of 12 th grade aptitude and achievement measures. He also estimates a model of the wages associated with each of these outcomes. He uses the education outcome probabilities and the wage payoffs to compute the ex ante return to starting college as a function of student characteristics. The ex post payoffs matter in proportion to the probability that they will be realized. He provides estimates for men and women of the effects of family background, high school curriculum, and aptitude and achievement on the ex ante return to starting college. Students with higher ex ante returns are more likely to start college and 12 th graders who expect to attend college have a higher ex ante return. Stange (2011) estimates a dynamic structural model of education choice which shows that the option value of early choices can be substantial. See also Heckman et al (2008). Neither Stange nor Heckman et al consider field of study. See Altonji (1993) for references to a few earlier papers that consider the implications of uncertainty about completion probabilities in examining the demand for and return to education, including Manski (1989). Weisbrod (1962) introduced the concept of the financial option value of a year of education.
} 
the variance as well as the mean of earnings associated with particular programs of study. (Table 1 reports 10th and 90th percentiles of wages by major.) Saks \& Shore (2005) find that students from wealthier families are more likely to choose "riskier" majors, as is implied by a model in which agents have decreasing absolute risk aversion. Christiansen et al (2007) investigate the risk-return trade-off in major choice and conclude that many majors are not at the efficient frontier. However, their model excludes effort costs and other costs, so the frontier interpretation may be overly restrictive.

\subsection{Preferences}

A number of studies examine the effects of preferences for non-pecuniary aspects of majors and their associated occupations on choice of major. Daymont \& Andrisani (1984) make use of survey questions regarding the importance an individual assigns to various job characteristics (being a leader, working with people, making lots of money, helping others). They find substantial gender differences in in the measures. Their multivariate regression analysis indicates that the preference measures account for nearly a third of the gender difference in choosing a business major is explained by these variables but play only a minor role other majors. However, this paper does not include ability controls or test scores.

Blakemore \& Low (1984) find that women tend to choose majors that are subject to less atrophy, reducing the costs of time away from the labor market for child care. Turner and Bowen (1999) also outline stark gender differences in major choice but point out this could be due to differences in preferences or to the "chilling" effect of past labor market discrimination. They also highlight the importance of finer degrees of disaggregation in major choice, pointing out that biology and physics, while often grouped together, in fact require very different skill sets.

Zafar (2009a) is principally interested in decomposing gender differences into differences in abilities and preferences. He finds that preferences play a strong role. For example, in addition to expected future earnings, students care about enjoying coursework, parental approval, and the social status of future occupations. ${ }^{23}$ Moreover, while the choices of men depend roughly equally on pecuniary and non-pecuniary attributes, women's choices depend roughly twice as much on non-pecuniary attributes than pecuniary ones. Stinebrickner and Stinebrickner (2011) find that student preferences and ability play a crucial role in field of study.

\subsection{Ability and preparation}

We have not yet said anything about how high school preparation and innate ability conditions choice of major. Turner \& Bowen (1999) show that the effects of SAT scores (math and verbal) are non-linear and, moreover, that the effects differ by gender. These scores account for $45 \%$ of the gender gap in math/physical sciences, but only $8 \%$ in psychology, leaving a great deal of room for gender differences in preferences. Zafar (2009a) also rules out gender differences in beliefs about ability as a driver of gender differences in choices.

\footnotetext{
${ }^{23}$ Other papers in the large literature in economics and other fields on gender differences in major choice include Dickson (2010) and Canes and Rosen (1995).
} 
Stinebrickner \& Stinebrickner (2011) use a unique panel data set on Berea College students to track student major choices over time. Rather than asking students to state their expected major, they ask the students to assign probabilities to completing various majors (see also Manski (1993) and Manski (2004)). They find that although many students begin their college careers assigning a high probability to finishing a science major, many learn that their abilities are not adequate. In our model, we incorporate this new information about one's abilities through performance shocks in college. Ost (2010) echoes Stinebrickner \& Stinebrickner (2011) and Arcidiacono (2004) in documenting a positive relationship between grades and persistence in a particular major. However, Ost points that physical science majors get higher grades in non-science courses than in science courses and thus may be tempted away from science. This effect is exacerbated by increasing grade inflation in non-science fields relative to science fields. He finds additionally that the presence of high-achieving peers in the physical sciences positively influences one's own persistence. It is somewhat artificial to separate ability and preparation from preferences in determining major choice. Ability to pursue a particular course of study with a reasonable level of effort and to perform well in related jobs influences the utility associated with the activity, holding wages constant.

\section{Returns to college major: empirical evidence}

Here we provide a partial survey of the literature on returns to college curriculum. We also present descriptive estimates of returns to different majors using data from the ACS, supplemented with characteristics associated with different majors (average SAT scores, numbers of math and science courses, etc) extracted from the Baccalaureate and Beyond 1993 dataset. We begin with a discussion of the estimation strategies used and possible alternative ones. We then turn to the results.

\subsection{Estimation strategies in the existing literature}

Estimating the returns to college major is fraught with many of the same difficulties that plague estimations of the average return to schooling more generally. The main problems are omitted variables that influence both choice and earnings, and selection bias based on heterogeneity in returns. To the extent that students select into particular majors on the basis of their anticipated future returns, OLS estimates of the returns will be biased as estimates of the causal impacts of major choice. As such they will represent neither the average treatment effect, nor the effect of treatment on the treated..$^{24}$ Most papers nevertheless use OLS and hope that controls are adequate.

Berger (1988) is one of the few papers that attempts to address this kind of selection. He uses a conditional logit with five major categories and finds that students choose majors on the basis of the present value of expected lifetime earnings. To obtain identification, he allows family background variables (father's occupation, parental education, race, etc) to affect the choice of major without affecting earnings and allows ability measures (IQ, Knowledge of World of Work) and cohort to affect major choice only through the earnings equation. Both of these assumptions are

\footnotetext{
${ }^{24}$ Sample selection bias associated with labor force participation is also an issue, as Hamermesh and Donald (2008) show (see below). Few studies address it.
} 
questionable. There is clear evidence that the psychic costs and benefits of college depend on ability and performancesee for example Arcidiacono (2004). Furthermore, family background might easily affect general skills and may thus influence earnings as well as the payoff to particular majors. ${ }^{25}$

The coefficient on the selection correction term is found to be significant for only two majors within each specification (education and liberal arts in the case of $\log$ wages; education and science in the case of log earnings). While Berger interprets the signs on these coefficients as indicative of positive selection, the lack of consistency across specifications and lack of significance leaves room for doubt.

The final approach is to use a dynamic discrete choice model along the lines of Section 2. Arcidiacono (2004) uses this approach.

\subsection{Possible alternative strategies}

Other methods to control for selection in major choice do not appear to have been used. If there were sufficient regional variation in offerings across colleges, such as the availability of an engineering school, a variant of Card's (1995) "distance to college" instrument might be tried. Freeman (1976) and Siow (1984), among others, show that the supply to specific occupations depends upon market conditions at the time that students choose a field of study. More work could be done using variation across time and place in the demand for particular types of majors. However, the work of Lisa Kahn (2010), Paul Oyer (2006) and others indicates that market conditions at the time of labor market entry have long-term effects on earnings prospects. Consequently, one might question whether labor market conditions early in college can be excluded from wage equations even several years after graduation. Perhaps parental occupation or college major could be used if parental earnings, assets, highest degree level, and ability are controlled for.

A natural approach would be to use a regression discontinuity (RD) design in situations where certain majors have a test score cut-off or enrollment cap for entry. Some US universities use GPA cut-offs as a way to ration access to some programs. The opportunity for RD approaches is greater in countries that admit students to particular programs and particular colleges based primarily on test scores. ${ }^{26}$ However, because students are in fact making a sequence of decisions about whether to remain in school and about which field to choose (particularly in the US context), there is an important distinction between ex ante and ex post returns to schooling decisions. Both of these returns to school choice depend on when the choice is made. The ex post return parameter to graduating in engineering identified by a regression discontinuity design based on grades or test scores at the time of college entry is different from the corresponding parameter identified using a grade cutoff after the second year of college.

Another selection issue is selection into the labor force. Employment rates differ substantially across majors both because of differences in labor force attachment and differences in the unemployment probability. Insofar as this problem is restricted to women, one "solution" is to estimate wage equations for men only, as is standard in the returns

\footnotetext{
${ }^{25}$ See also Willis and Rosen (1979).

${ }^{26}$ Depending on the institutional details, one must address selection in the decision to apply to particular universities and programs. See Carvalho and Magnac (2010) for an example of such a study of college and major choice for Brazil. With additional data, their analysis could be extended to labor market outcomes. Bertrand et al (2010) apply an RD strategy based on admissions cut-off scores to engineering colleges in India that vary across castes, although large sampling errors limit what they can conclude about earnings effects.
} 
to schooling literature more generally. However, this sidesteps many interesting and important questions regarding gender differences in choice of, and returns to, college major, and it does not address differential unemployment risk. Hamermesh and Donald (2008) is the only paper we reviewed that explicitly corrects for selection into employment. ${ }^{27}$ They find that accounting for selection into the labor force reduces earnings differentials across major by $10-20 \%$. Furthermore, this bias is most important for education majors, which is not surprising given the much larger proportion of female education majors and the fact that Hamermesh and Donald pool men and women. This points to the importance of an integrated approach where both employment and earnings prospects play a role in choosing major and employment selection is controlled for.

\subsection{Estimates of the return to major}

As we already noted, most studies use OLS with control variables rather than addressing endogenous selection into college major with an IV strategy or a selection model with exclusion restrictions. The control variables range from simple demographics, a small set of family background measures, and perhaps test scores, to detailed high school transcript information. The case for controlling for high school grades, tests, and courses prior to college seems clear. However, omitted variables bias in estimates of the effects of these variables could spill over into bias in estimates of returns to major. Some studies control for college transcript information and college quality measures. Some also include performance measures in college, arguing that insofar as ability differs by major, the returns to college major may be conflated with returns to ability. Whether one includes college variables, such as "semesters of math," depends on whether one wishes to measure the total effect of a particular college major (including human capital accumulation in the form of coursework and grades) or the effect of the title of the degree, net of substantive skill differences. Hamermesh and Donald (2008) show that there is a substantial return to upper-level math and science credits and grades holding eleven major categories constant. (Explaining differences in the returns to majors with differences in course content and grades, as opposed to the credential effect of the field of degree, is an interesting challenge for research.) Controlling for occupation is hard to defend other than as part of a strategy to identify why majors pay differently.

Table 2 presents certain estimates from selected papers. Aside from methodological concerns and differences in control variables, caution is urged in comparing results across studies for two main reasons. First, the level of aggregation of majors differs widely from study to study, ranging from four to over ten. Second, the time periods in question vary somewhat, although many use the same data set (NLS72). The estimates shown are the coefficients on major dummies in OLS regressions with the specified control variables. ${ }^{28}$ Coefficients for men and women are presented separately when available. For ease of comparison, coefficients have been re-calculated, when necessary, relative to the education major; significance levels are not reported unless education was the original excluded category in the study.

As has been well-documented, the return to skill has increased substantially over the past few decades, particularly

\footnotetext{
${ }^{27}$ They also model survey non-response, but find that this has a negligible effect on results.

${ }^{28}$ The exception is Berger (1988), who runs separate regressions for each major category. The estimates shown are the premiums (over education) in predicted $\log$ wages.
} 
in the 1980s. Grogger and Eide (1995) decompose this into a change in returns and a change in the composition of majors. ${ }^{29}$ In particular, they find that the return to math ability increased substantially for women, while a trend toward more technical subjects accounted for much of the increase for men. The coefficients presented in the table are the coefficients on the major; however, the authors also include major interacted with experience and experiencesquared, whose coefficients are not shown. ${ }^{30}$

Overall, however, the relative results have remained remarkably consistent over time. In particular, engineering consistently commands a high premium (around 0.40 relative to education), usually followed by business and science. Humanities, social sciences, and education are further behind. Controlling for pre-college test scores and grades reduces earnings differentials substantially. Hamermesh and Donald (2008), for example, report a standard deviation of 0.305 points of log earnings differences across twelve majors; this is halved when GPA, upper division math courses, upper division math grades, annual hours worked and a few additional controls are included. Controlling for selection into the labor force and non-response bias reduces the standard deviation somewhat further, to 0.139.

There has been speculation that the difference in returns is due to difference in math ability. Paglin and Rufolo (1990), for example, explain $82 \%$ of the variance across college majors in entry-level wages on the basis of the average GRE-math scores by major. ${ }^{31}$ Moreover, Grogger and Eide show that the return to math ability has increased over time: the effect of a one standard deviation increase in math ability grew from a $2 \%$ increase in wages in 1978 to $5 \%$ in 1986 , and from $3 \%$ to $7.5 \%$ for women.

There are also differences across majors in hours worked. Hamermesh and Donald (2008) find that controlling for hours worked and selection into the workforce reduces earnings differentials.

One might also be interested in the effects of college major on occupation, and in particular, the extent to which human capital is major-specific. Robst (2007) shows that students who are employed in a field unrelated to their field of study suffer a wage penalty, suggesting that this is at least partially the case; however, the wage penalty varies by field. The most specific fields, such as engineering, involve harsher penalties than fields which develop more general skills, such as liberal arts. Malamud (2011), however, shows that the British system that requires students to specialize early leads to greater field-switching upon labor market entry than the Scottish system, which allows later specialization. This suggests that delaying specialization to learn about one's preferences and comparative advantage may outweigh any loss in field-specific skills.

Not much is known about the effect of college major on opportunities at the graduate level. Black et al (2003)

\footnotetext{
${ }^{29}$ These changes in composition are documented in Section 5.

${ }^{30}$ Several other studies address the contribution of major choice to the gender gap among college graduates, including the recent study by Black et al (2008), who provide additional references. Black et al use the National Survey of College Graduates, which provides large sample sizes, highly disaggregated major categories and a measure of full-time experience. Results differ somewhat across race/ethnic groups, but for whites the unexplained gender gap is -0.184 when highest degree, highest degree major field, and age are controlled for, compared to a total gap of -0.339 . For workers with high labor force attachment, the unexplained gap is -0.086 and the total gap -0.297 . Black et al (2006) provide a similar analysis of the contribution of differences in detailed major to race differentials in the wages of highly educated men. Among individuals who speak English at home, differences in education and language proficiency account for essentially all of the small gap between white men and Hispanic men but only a quarter of the much larger gap between white men and black men. The reduction in the gap is about the same for the two groups. However, they account for the entire gap for black men born outside the South with parents who have some education.

${ }^{31}$ See also Weinberger (1999). Some of this reflects the effect of major on math scores, and association between average math scores and other student characteristics. In the ACS data we "explain" about $58 \%$ of the variance in the major-specific returns with SAT math and verbal scores.
} 
provide estimates of wage gaps by undergraduate major relative to economics for those who obtain an MBA or a graduate law degree. With the exception of chemical engineers who obtain an MBA, economists earn more than their counterparts from the other most common pre-MBA or pre-law majors. These results illustrate the importance of considering the options that an earlier education choice offers.

\subsection{Descriptive evidence from the ACS on college major choice and returns}

In this subsection we provide additional evidence on the relative returns to college major using the ACS. Unfortunately, the data set lacks test scores and family background measures, and so the estimates we report almost certainly overstate the relative return to majors that attract advantaged, high ability students. Nevertheless the large size of the ACS permits one to examine very detailed major categories with and without 5 -digit occupation controls and to examine trends in major choice by graduation cohort and gender. Table 3 provides OLS estimates of major coefficients separately for men and women, with and without occupation controls. These regressions include dummy variables for advanced degrees, a cubic in potential experience, and race/ethnicity as controls. The table reports only the 23 most popular of the 171 major categories included in the regression. These twenty-three account for just over half of the college-plus sample. The omitted category is General Education. Near the bottom of the table we also report the sample-weighted standard deviation of the major coefficients adjusted for sampling error. ${ }^{32}$ The differences across majors are large. Consistent with results in the literature, the estimates show that engineers have the highest returns and education majors the lowest. This is true even after controlling for occupation. In most fields the size of the premium over a general education degree is higher for men than it is for women. The standard deviation is 0.177 for men and 0.146 for women. Thus, for men (women), a two standard deviation shift is associated with an increase of 0.354 (0.292) log points in earnings. To compare, the high school-college differential is $0.577 .^{33}$ Almost all of the gender difference in the standard deviation is due to gender differences in major choice rather than gender differences in the dispersion of the major coefficients.

How have trends in major choice affected the gender gap holding the major coefficients for men and women constant? Figure 2 takes the major coefficients from Table 3 and calculates their weighted average by age and gender. (General education is the omitted category.) For individuals who graduated from college in the early 1970s, the weighted average of the female coefficients using the male major weights is about 0.1 above the value using the female weights. The gap narrows for the later cohorts but does not move very much. The gap at the beginning of the period is even wider using the male weights, but it narrows during the 70s. These results indicate that over most of the period, the differences in college major choice account for about a third of the gender gap in log wages.

The figure also show how changes in the composition of majors have affected the average return to a college degree.

\footnotetext{
${ }^{32}$ The sample is restricted to individuals between 23 and 59 years of age who worked more than 34 hours a week for more than 40 weeks in the previous year and who had a college or advanced degree. All majors are included, not just those corresponding to the coefficients presented in the table. The full set of coefficients are in Supplementary Table 3. See Carnevale et al (2011) for a descriptive analysis of the returns to college major using the ACS.

${ }^{33}$ This is the coefficient on a college degree dummy in a regression that excludes the college major indicators, includes education level indicators and the other controls used in Table 3, and is estimated on a sample that includes high school graduates and above.
} 
For both men and women, the curves show an increase of about 0.05 in the weighted average of the returns between the early 1970s and about 1986. This is due to a shift toward more lucrative majors, particularly engineering and business, with a peak in the mid-80s. The figure shows a decline of about 0.02 after that. These shifts in the distribution of majors are illustrated in Supplementary Figure 1.

We have also estimated, but do not present, a set of regressions using major characteristics from the B\&B and the demographic and educational variables used above. Including $51 \mathrm{~B} \& \mathrm{~B}$ major dummies yields an $R^{2}$ of 0.261 , an increase of 0.06 over the $R^{2}$ of a model with only highest-degree indicators. Replacing the major dummies with major-specific SAT scores ${ }^{34}$ (math and verbal) or including counts of the average number of courses in 8 different disciplines (math, business, etc) leads to $R^{2}$ values of 0.234 and 0.241 , respectively. SAT scores account for $54.7 \%$ of the variation in the return to college major across the B\&B categories (weighted by frequency in the ACS sample). We obtain $62.5 \%$ of the variation using average GRE math, verbal, and writing scores for graduate school applicants in a smaller number of major categories. However, this overstates the role pre-existing ability differences for reasons touched upon earlier.

What is the role of occupation? For men, the standard deviation of the college major coefficients is 0.177 when occupation is excluded and 0.098 when it is controlled for. Thus a substantial part of the difference in pay across majors is related to the occupations that they lead to. Part of this wage difference represents compensating differentials for nonpecuniary factors, of course.

In summary, wages vary greatly across college major. The variation is large enough for the tendency for men to choose high paying majors to be an important factor in the gender gap in wages. A substantial part of the differences in returns is almost certainly due to differences in the market value of tasks that require the specific knowledge and skills particular majors develop. However, pre-college differences in skill and ability, as captured by the SAT scores, and compensating differentials for nonpecuniary attributes also play a role. Much remains to be learned about why majors pay so differently.

\subsection{College major and occupational choice}

In this subsection we discuss the empirical link between college major and occupation. ${ }^{35}$ For some majors, such as nursing and accounting, the path is clear. For others it is not. Supplementary Table 4 illustrates the proportion of graduates in various majors employed in the three most common 5-digit occupations for that major. About $70 \%$ of accounting or auditing majors aged 25-29 are employed in the top three occupations. Even among those aged 55-59, the figure is $51 \%$. For nursing, the comparable figures are 90 and $79 \%$. On the other hand, history and psychology are examples of majors that have high occupational dispersion at all ages. Overall, the table suggests a "fanning-out" of occupations as individuals are promoted or switch occupations as their careers progress. Figure 3 provides further

\footnotetext{
${ }^{34}$ SAT Math and Verbal scores are predicted using the combined SAT Math and Verbal scores when the math and verbal scores are missing.

${ }^{35}$ Ransom and Phipps (2010) provide related evidence on the link between major and occupation using the National Survey of College Graduates.
} 
evidence for this pattern. This figure reports the probability density (across majors) of the fraction of people in a major who are in one of the top ten occupations for that major. The peak of the densities occurs when the fraction is about 0.43. However, the heavy right tail and lower peak for those aged 25 to 34 indicates that occupational concentration is substantially larger for young workers.

The flip side of this analysis is the proportion of workers in an occupation accounted for by the three most common majors for that occupation. In Supplementary Table 5 we report this statistic for a few occupations by stage of career. Not surprisingly, almost all registered nurses major in either nursing, biology, or psychology regardless of stage of career. The values for marketing and sales managers and for accountants and auditors are similar, though less extreme. Post-secondary school teachers and marketing and sales are examples of occupations that draw on a wider array of majors. With a large panel data set, one could go much further in examining the link between major and career path. We have already noted that much the variance in the returns to majors is associated with differences in the pay of the occupations that they lead to. The clear message is that specificity of skill is important to a degree that varies across occupation and major.

\section{Conclusion}

The demand for and return to types of human capital investments is an exciting research area that is highly relevant for both education and labor market policy, as education and occupation choices differ greatly in the monetary and non-monetary rewards that they bring.

Rather than summarizing the paper, we close by restating the questions for empirical research. The recent theoretical work on education and occupation choice that we have synthesized here emphasizes several key factors: the sequential nature of the decision-making process; the partial irreversibility of some decisions because of the heterogeneity of human capital and the cumulative nature of human capital investment in many fields; the importance of innate ability, preferences, and pre-high school learning in shaping the feasibility and non-pecuniary costs and benefits of particular education and occupation paths; and the essential role of uncertainty about ability, preferences, knowledge accumulation, and wage rates at each stage. The theory has some very clear implications for empirical research. The first concerns the determination of preferences for schooling in general and types of schooling in particular, which we touch on briefly in Section 3. The second concerns the determination of the ability to do math, excel at science, write well, etc. The third concerns estimation of the knowledge production function. How should skills and knowledge be classified? How can they be measured using observables such as course content, grades, and tests? How much does learning in school or on the job depend on the program or the occupation? The fourth is how grades, knowledge and ability determine promotion and admission to colleges, a subject on which there is a substantial literature that we have not touched on here. The fifth is how best to model the agent's information set and learning about ability and preferences. The sixth is estimation of the ex post payoff to knowledge, ability, and degree by level and field. We summarized a number of papers that attempt this for college education and a smaller number that look at high school 
curriculum. Much progress has been made, but there is a long way to go on the road to credible measures of the payoff to fields of study. We suggest several approaches that might prove fruitful.

The overriding question is the choice of education and occupation at each stage in the life course and the consequences of those choices. For example, how does the current utility and expected future utility of spending the first period of college in a pre-engineering curriculum versus a fine arts curriculum depend on preferences, ability, and the stock of human capital at the start of college? The large earnings gaps across fields that attract students admitted to the same universities with similar grades and test scores strongly suggests that compensating differentials are of critical importance.

\section{References}

[1] Altonji JG. 1993. The demand for and return to education when education outcomes are uncertain. $J$. Labor Econ. 11(1):48-83

[2] Altonji JG. 1995. The effects of high school curriculum on education and labor market outcomes. J. Hum. Resour. 30(3):409-38

[3] Altonji JG, Pierret CR. 2001. Employer learning and statistical discrimination. Q. J. Econ. 116(1):313-350

[4] Arcidiacono P. 2004. Ability sorting and the returns to college major. J. Econom. 121(1-2):343-75

[5] Arcidiacono P, Hotz VJ, Kang S. 2010. Modeling college major choices using elicited measures of expectations and counterfactuals. IZA Disc. Pap. 4738

[6] Berger MC. 1988. Predicted future earnings and choice of college major. Ind. 63 Labor Relat. Rev. 41(3):418-29

[7] Bertrand M, Hanna R, Mullainathan S. 2010. Affirmative action in education: evidence from engineering college admissions. J. Pub. Econ. 94(1-2):16-29

[8] Betts JR. 1996. What do students know about wages? Evidence from a survey of undergraduates. $J$. Hum. Resour. 31(1):27-56

[9] Black DA, Haviland AM, Sanders SG, Taylor LJ. 2006. Why do minority men earn less? A study of wage differentials among the highly educated. Rev. Econ. Stat. 88(1):300-13

[10] Black DA, Haviland AM, Sanders SG, Taylor LJ. 2008. Gender wage disparities among the highly educated. J. Hum. Resour. 43(3):630-59

[11] Black DA, Sanders S, Taylor L. 2003. The economic reward for studying economics. Econ. Inquiry $41(3): 365-77$ 
[12] Cameron SV, Heckman JJ. 1998. Life cycling schooling and dynamic selection bias: models and evidence for five cohorts of American males. J. Pol. Econ. 106(2):262-333

[13] Canes BJ, Rosen HS. 1995. Following in her footsteps? Faculty gender composition and women's choice of college majors. Ind. \& Labor Relat. Rev. 48(3):486-504

[14] Card DE. 1995. Using geographic variation in college proximity to estimate the return to schooling. In Aspects of Labor Market Behaviour: Essays in Honour of John Vanderkamp, ed. Christofides LN, Grant EK, Swidinsky R, 201-22. Toronto: University of Toronto Press

[15] Card DE. 1999. The causal effect of education on earnings. In Handbook of Labor Economics, ed. Ashenfelter O, Card DE, 3A. Amsterdam: Elsevier

[16] Carnevale AP, Strohl J, Melton M. 2011. What's it worth? The economics value of college majors. Center on Education and the Workforce, Georgetown University

[17] Carvalho JR, Magnac T. 2010. College choice and entry exams. Work. Pap., CAEN, Universidade Federal do Ceara, Fortaleza, Brazil and Toulouse Sch. Econ., Toulouse, France

[18] Christiansen C, Joensen JS, Nielsen HS. 2007. The risk-return trade-off in human capital investment. Labour Econ. 14(6):971-86

[19] Currie J. 2009. Healthy, wealthy, and wise: socioeconomic status, poor health in childhood, and human capital development. J. Econ. Lit. 47(1):87-122

[20] Daymont TN, Andrisani PJ. 1984. Job preferences, college major, and the gender gap in earnings. $J$. Hum. Resour. 19(3):408-28

[21] Dickson L. 2010. Race and gender differences in college major choice. Annals Amer. Acad. Pol. E5 Soc. Sci. $627(1): 108-24$

[22] Eckstein Z, Wolpin KI. 1989. The specification and estimation of dynamic stochastic discrete choice models: a survey. J. Hum. Resour. 24(4):562-98

[23] Eide E, Waehrer G. 1998. The role of the option value of college attendance in college major choice. Econ. Educ. Rev. 17(1):73-82

[24] Farber HS, Gibbons R. 1996. Learning and wage dynamics. Q. J. Econ. 111(4):1007-47

[25] Freeman R. 1976. A cobweb model of the supply and starting salary of new engineers. Ind. ES Labor Relat. Rev. 29(2):236-48

[26] Gardner DP. 1983. A nation at risk: the imperative for educational reform. Washington, DC: National Commission on Excellence in Education 
[27] Gathmann C, Schönberg U. 2010. How general is human capital? A task based approach,” J. Labor Econ. 28(1):1-50

[28] Goldin C, Katz LF, Kuziemko I. 2006. The homecoming of American college women: The reversal of the gender gap in college. J. Econ. Perspect. 20(4):133-56

[29] Goodman J. 2009. The labor of division: returns to compulsory math coursework. Work. Pap., Harvard Kennedy School

[30] Grogger J, Eide E. 1995. Changes in college skills and the rise in the college wage premium. J. Hum. Resour. 30(2):280-310

[31] Hamermesh DS, Donald SG. 2008. The effect of college curriculum on earnings: an affinity identifier for non-ignorable non-response bias. J. Econom. 144(2):479-91

[32] Heckman JJ, Honore BE. 1990. The empirical content of the Roy model. Econom. 58(5):1121-49

[33] Heckman JJ, Lochner LJ, Todd PE. 2008. Earnings functions and rates of return. J. Human Capital. 2(1):1-31

[34] Heckman JJ, Masterov DV. 2007. The productivity argument for investing in young children. Appl. Econ. Perspect. Pol. 29(3):446-93

[35] Heckman JJ, Navarro S. 2007. Dynamic discrete choice and dynamic treatment effects. J. Econom. 136(2):341-96

[36] Heckman JJ, Robb R. 1985. Using longitudinal data to estimate age, period, and cohort effects in earnings equations. In Cohort Analysis in Social Research: Beyond the Identification Problem, ed. Mason W, Fienberg S. New York: Springer Verlag

[37] Imbens GW, Angrist JD. 1994. Identification and estimation of local average treatment effects. Econom. $62(2): 467-75$

[38] Joensen JS, Nielsen HS. 2009. Is there a causal effect of high school math on labor market outcomes? $J$. Hum. Resour. 44(1):171-98

[39] Kahn LB. 2010. The long-term labor market consequences of graduating from college in a bad economy. Labour Econ. 17(2):303-16

[40] Keane MP, Wolpin KI. 1997. The career decisions of young men. J. Pol. Econ. 105(3):473-522

[41] Lange F. 2007. The speed of employer learning. J. Labor Econ. 25(1):1-35

[42] Lazear E. 2009. Firm-specific human capital: a skill-weights approach. J. Pol. Econ. 117(5):914-940 
[43] Levine PB, Zimmerman DJ. 1995. The benefit of additional high-school math and science classes for young men and women. J. Bus. \&3 Econ. Stat. 13(2):137-49

[44] Malamud O. 2011. Discovering one's talent: learning from academic specialization. Ind. Es Labor Relat. Rev. 64(2):375-405

[45] Mane F. 1999. Trends in the payoff to academic and occupation-specific skills: the short and medium run returns to academic and vocational high school courses for non-college-bound students. Econ. Educ. Rev. 18(4):417-37

[46] Manski CF. 1989. Schooling as experimentation: a reappraisal of the postsecondary dropout phenomenon. Econ. Educ. Rev. 8(4):305-12

[47] Manski CF. 1993. Adolescent econometricians: how do youth infer the returns to schooling? In Studies of Supply and Demand in Higher Education, 43-60. NBER

[48] Manski CF. 2004. Measuring expectations. Econometrica. 72(5):1329-76

[49] Meghir C, Rivkin SG. 2011. Econometric methods for research in education. In Handbook of the Economics of Education, ed. Hanushek E, Machin S, Woessmann L, 3(3):1-87. Elsevier

[50] Montmarquette C, Cannings K, Mahseredjian S. 2002. How do young people choose college majors? Econ. Educ. Rev. 21(6):543-56

[51] Ost B. 2010. The role of peers and grades in determining major persistence in the sciences. Econ. Educ. Rev. 29(6):923-34

[52] Oyer P. 2006. Initial labor market conditions and long-term outcomes for economists. J. Econ. Perspect. 20(3):143-160

[53] Paglin M, Rufolo AM. 1990. Heterogeneous human capital, occupation choice, and male-female earnings differences. J. Labor Econ. 8(1):123-44

[54] Papageorgiou T. 2010. Learning your comparative advantages. PhD thesis. Yale Univ.

[55] Poletaev M, Robinson C. 2008. Human capital specificity: evidence from the dictionary of occupational titles and displaced worker surveys 1984-2000. J.Labor Econ. 26: 387-420.

[56] President's Council of Advisors on Science and Technology. 2011. Prepare and inspire: K-12 education in science, technology, engineering, and math (STEM) for America's future. Executive Office of the President, Washington, DC.

[57] _ 2012. Engage and excel: producing one million additional college graduates with degrees in science, technology, engineering, and mathematics. Executive Office of the President, Washington DC. 
[58] Quandt RE. 1972. A new approach to estimating switching regressions. J. Amer. Stat. Assoc. 67(338):30610

[59] Ransom M, Phipps A. (2010). Career and occupational implications of undergraduate majors: evidence from the National Survey of College Graduates, Brigham Young University. May.

[60] Robst J. 2007. Education and job match: the relatedness of college major and work. Econ. Educ. Rev. 26(4):397-407

[61] Rose H, Betts JR. 2004. The effect of high school courses on earnings. Rev. Econ. Stat. 86(2):397-513

[62] Rumberger RW, Daymont TN. 1984. The economic value of academic and vocational training acquired in high school. In Youth and the Labor Market, ed. M Borus, 157-92. Kalamazoo: WE Upjohn Institute for Employment Research

[63] Siow A. 1984. Occupational choice under uncertainty. Econometrica 52(3):631-45

[64] Stange KM. 2011. An empirical investigation of the option value of college enrollment. Am. Econ. J. In press

[65] Stinebrickner TR, Stinebrickner R. 2011. Math or science? Using longitudinal expectations data to examine the process of choosing a college major. NBER working paper 16869

[66] Todd PE, Wolpin KI. 2003. On the specification and estimation of the production function for cognitive achievement. Econ. J. 113(485):F3-F33

[67] Turner SE, Bowen WG. 1999. Choice of major: the changing (unchanging) gender gap. Indus. \& Lab. Rel. Rev. 52(2):289-313

[68] Violante G, Gallipoli G, Meghir C. 2005. Education decisions, equilibrium policies and wages dispersion. 2005 Meeting Papers 522, Soc. Econ. Dyn.

[69] Weinberger CJ. 1999. Mathematical college majors and the gender gap in wages. Ind. Relat. 38(3):407-13

[70] Weisbrod BA. 1962. Education and investment in human capital. J. Pol. Econ. 70(5):106-23

[71] Willis RJ, Rosen S. 1979. Education and self-selection. J. Pol. Econ. 87(5):S7-36

[72] Yamaguchi S. 2012. Tasks and heterogeneous human capital. J. Labor Econ. 30(1):1-53

[73] Zafar B. 2009. How do college students form expectations? Staff Report 378, Federal Reserve Bank, New York, NY

[74] Zafar B. 2009. College major choice and the gender gap. Staff Report 364, Federal Reserve Bank, New York, NY 


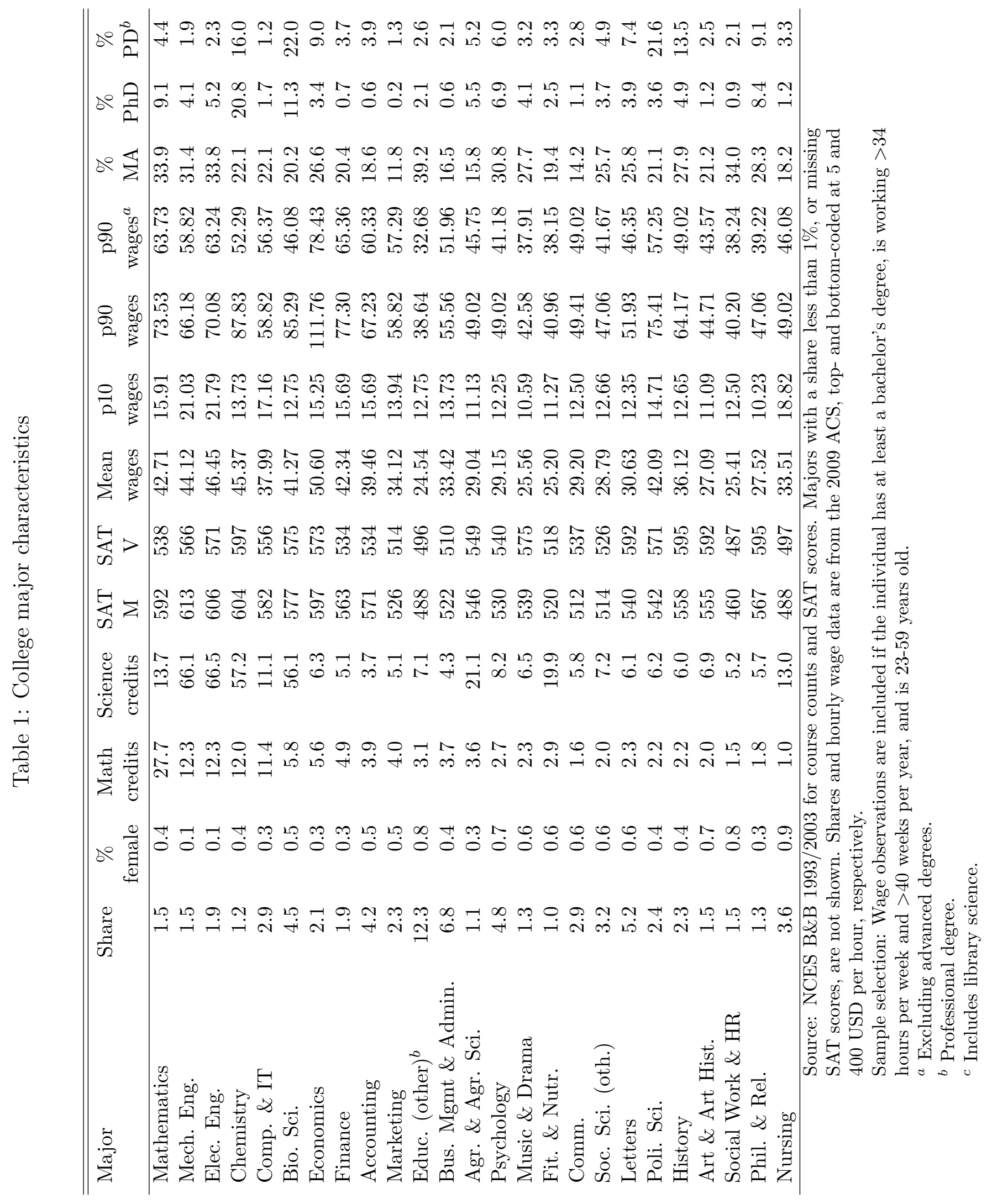




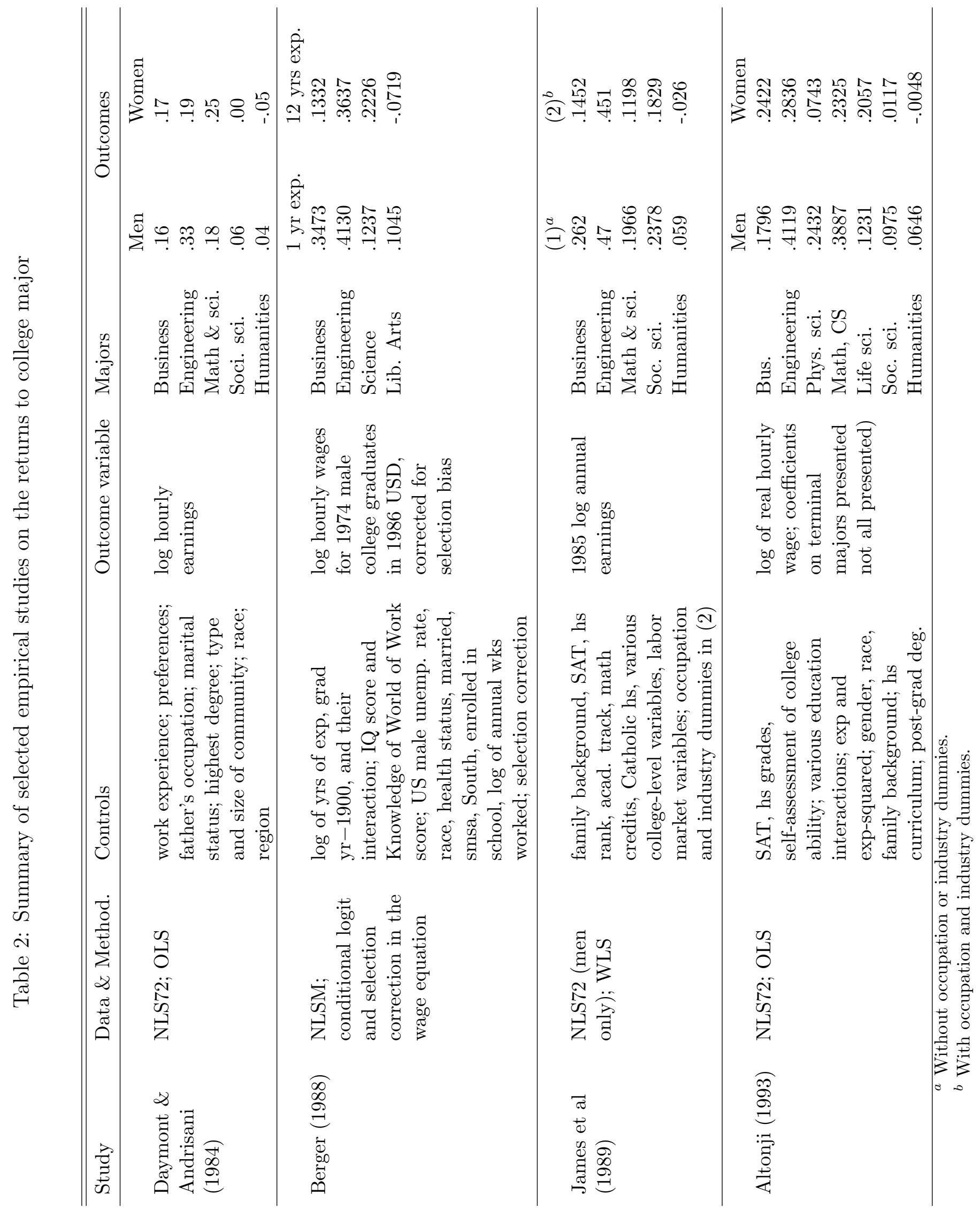




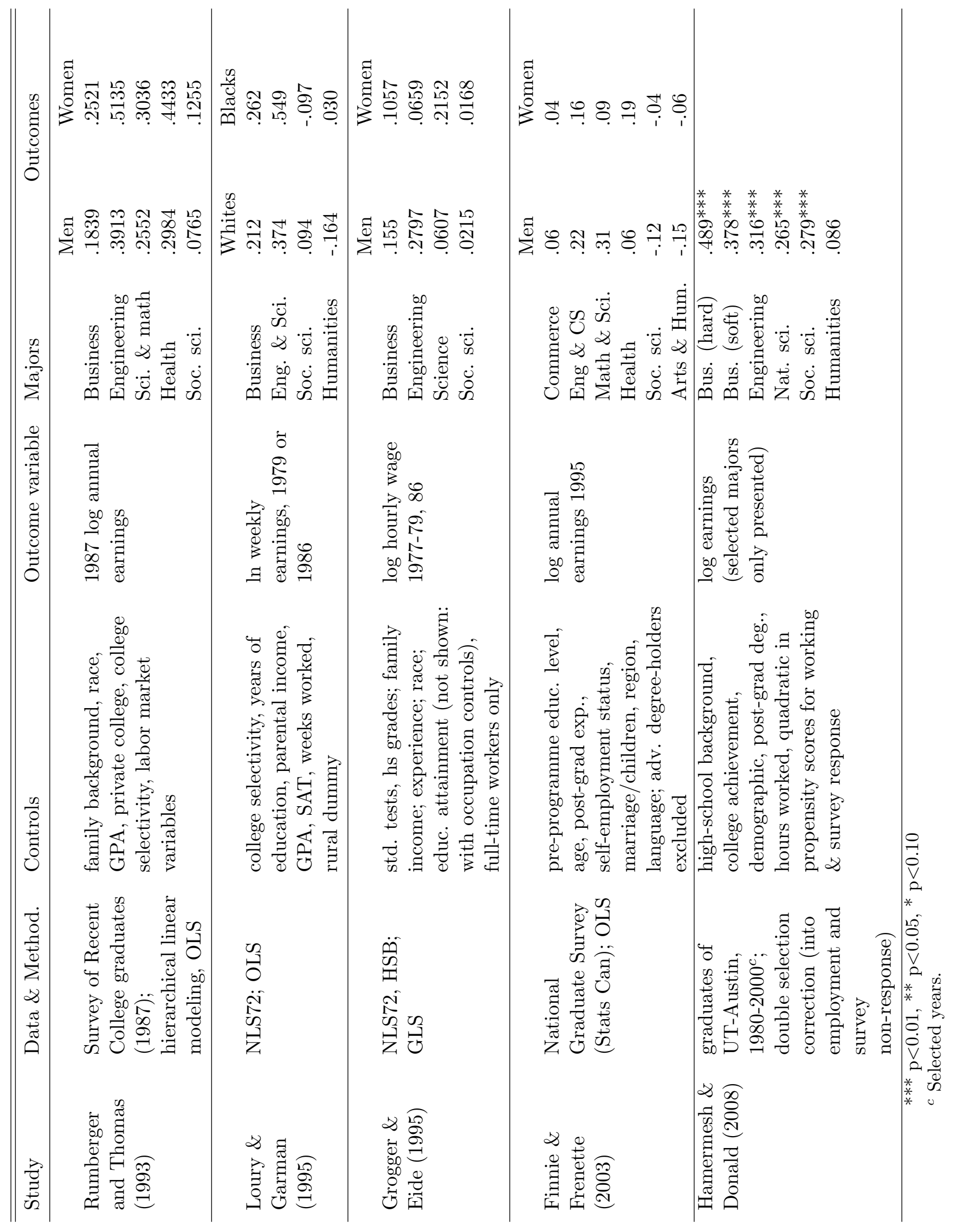


Table 3: Effects of college major on log wages by gender, with and without occupation controls

\begin{tabular}{lcccc}
\hline \hline Major & \multicolumn{3}{c}{ Major dummies only } & \multicolumn{2}{c}{ With occupation controls } \\
& Female & Male & Female & Male \\
\hline Communications & $0.202^{* * *}$ & $0.207^{* * *}$ & $0.063^{* * *}$ & $0.058^{* *}$ \\
Computer Science & $0.441^{* * *}$ & $0.531^{* * *}$ & $0.161^{* * *}$ & $0.242^{* * *}$ \\
Elementary Education & $-0.024^{*}$ & -0.009 & -0.015 & 0.009 \\
Electrical Engineering & $0.556^{* * *}$ & $0.561^{* * *}$ & $0.258^{* * *}$ & $0.293^{* * *}$ \\
Mechanical Engineering & $0.554^{* * *}$ & $0.524^{* * *}$ & $0.265^{* * *}$ & $0.264^{* * *}$ \\
English Language And Literature & $0.107^{* * *}$ & $0.152^{* * *}$ & $0.026^{*}$ & $0.063^{* * *}$ \\
Liberal Arts & $0.073^{* * *}$ & $0.154^{* * *}$ & 0.021 & $0.055^{*}$ \\
Biology & $0.196^{* * *}$ & $0.302^{* * *}$ & $0.068^{* * *}$ & $0.114^{* * *}$ \\
Mathematics & $0.288^{* * *}$ & $0.426^{* * *}$ & $0.143^{* * *}$ & $0.224^{* * *}$ \\
Chemistry & $0.250^{* * *}$ & $0.366^{* * *}$ & $0.101^{* * *}$ & $0.193^{* * *}$ \\
Criminal Justice And Fire Protection & $0.076^{* * *}$ & $0.226^{* * *}$ & -0.013 & $0.076^{* * *}$ \\
Economics & $0.400^{* * *}$ & $0.517^{* * *}$ & $0.224^{* * *}$ & $0.275^{* * *}$ \\
Anthropology And Archeology & $0.069^{* *}$ & $0.135^{* * *}$ & -0.001 & 0.053 \\
Political Science And Government & $0.246^{* * *}$ & $0.327^{* * *}$ & $0.112^{* * *}$ & $0.158^{* * *}$ \\
Sociology & $0.077^{* * *}$ & $0.165^{* * *}$ & 0.012 & $0.075^{* * *}$ \\
Fine Arts & -0.021 & 0.017 & $-0.067^{* *}$ & -0.035 \\
Nursing & $0.391^{* * *}$ & $0.408^{* * *}$ & $0.172^{* * *}$ & $0.243^{* * *}$ \\
General Business & $0.218^{* * *}$ & $0.339^{* * *}$ & $0.077^{* * *}$ & $0.142^{* * *}$ \\
Accounting & $0.310^{* * *}$ & $0.431^{* * *}$ & $0.143^{* * *}$ & $0.199^{* * *}$ \\
Business Management And Administration & $0.199^{* * *}$ & $0.292^{* * *}$ & $0.054^{* * *}$ & $0.104^{* * *}$ \\
Marketing And Marketing Research & $0.256^{* * *}$ & $0.356^{* * *}$ & $0.089^{* * *}$ & $0.150^{* * *}$ \\
Finance & $0.342^{* * *}$ & $0.518^{* * *}$ & $0.151^{* * *}$ & $0.243^{* * *}$ \\
History & $0.105^{* * *}$ & $0.167^{* * *}$ & $0.033^{*}$ & $0.064^{* * *}$ \\
\hline R & 0.200 & 0.217 & 0.330 & 0.337 \\
SD of major coefficients & 0.146 & 0.177 & 0.074 & 0.098 \\
N & 125794 & 140706 & 124858 & 139493 \\
\hline
\end{tabular}

Notes: ${ }^{* * *} \mathrm{p}<0.01,{ }^{* *} \mathrm{p}<0.05,{ }^{*} \mathrm{p}<0.10$

All specifications include dummy variables for highest level of education attained, a cubic in potential experience, and race dummies. Bachelor's degrees are 4-digit; only a selected sample of the 171 are shown. Wages are top- and bottom-coded at 5 and 400 USD per hour, respectively. General Education is the excluded category. Occupation controls are 5-digit. SD is calculated over all majors using ACS weights.

Sample selection: Observations are included if the individual has at least a bachelor's degree, is working $>34$ hours per week and $>40$ weeks per year, and is 23-59 years old. 
Figure 1: Relative fraction female, by major
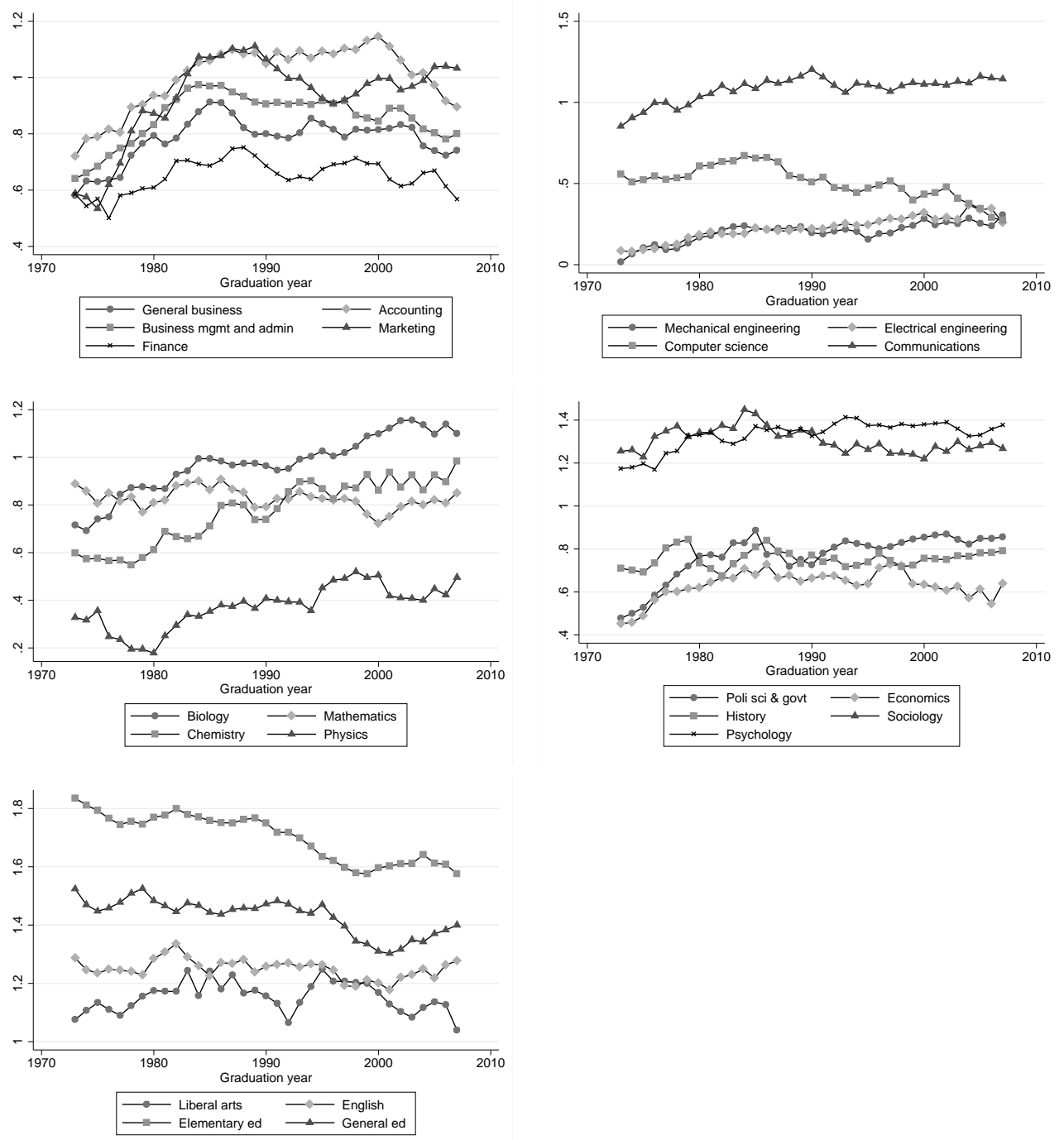

Note: Relative fraction female is calculated by dividing the fraction female in a particular major in a particular year by the fraction of female college graduates that year, then smoothed using a three-year moving average. Data are from the ACS. 
Figure 2: Average of major coefficients by age

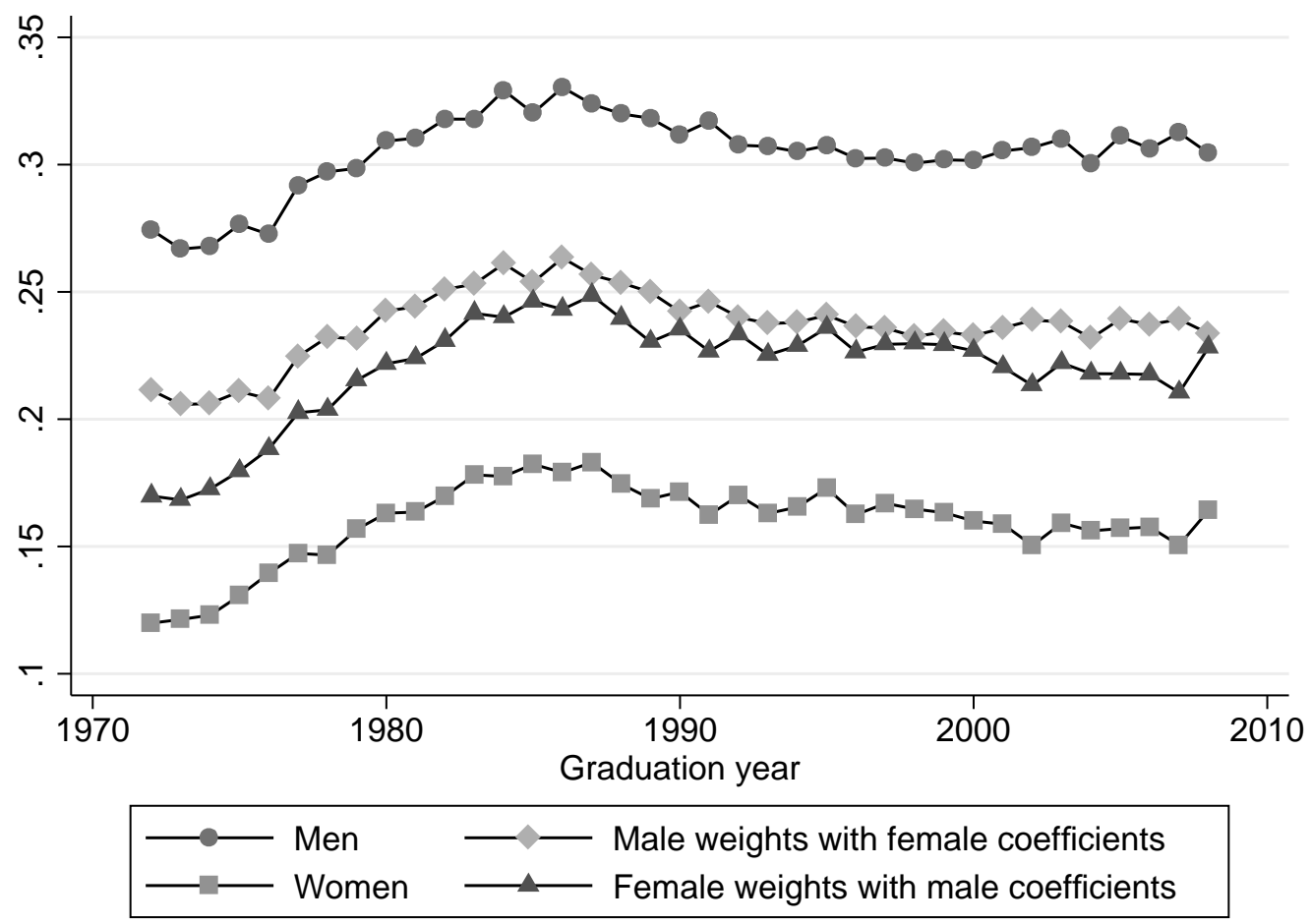


Figure 3: Occupational dispersion by age

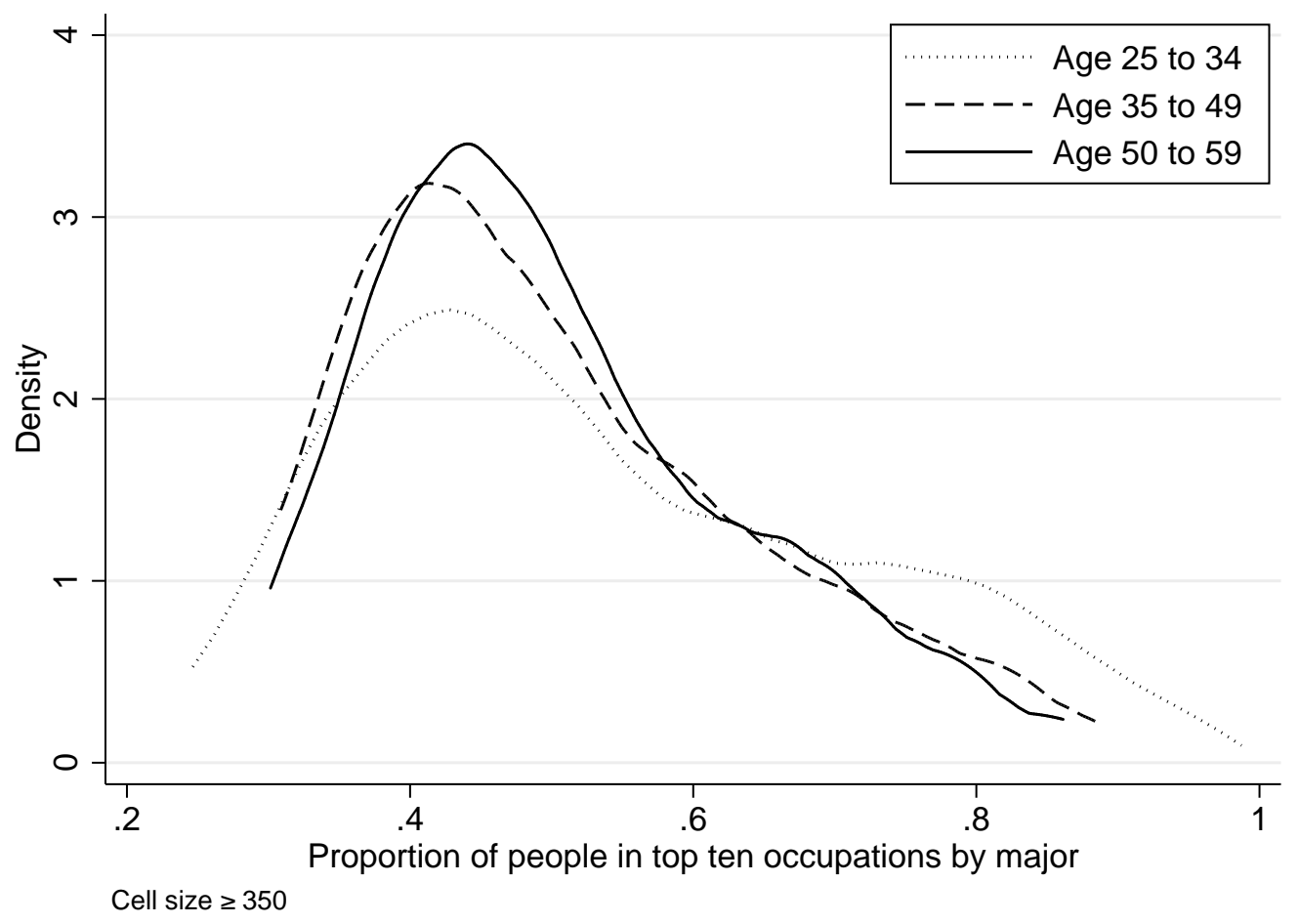




\section{WEB SUPPLEMENTAL APPENDIX}

\section{Empirical evidence on choice of high school curriculum}

There is relatively little empirical work in economics on how high school students choose curricula, particularly in comparison to research on choice of college major. The main margins of choice for a typical high school student are among vocational, general, and academic curricula, and, within the latter, between a focus in social sciences and humanities and a focus in mathematics and science. The level and number of courses (subject to promotion and graduation requirements) are also choice variables. Contrary to popular perception, the number and level of courses in academic subjects taken by high school students in America have risen over the past thirty years. Data on course taking by high school seniors reported in Ingels et al (2008) for the years 1982, 1992, and 2004 shows an increase from 1982, particularly in science. Supplementary Table 1 compares course-taking trends from 1990 to 2009 for high school graduates, as reported by Nord et al (2011). Course-taking overall is up and in core academic subjects (mathematics, science, social science, and English). Furthermore, the percentage of students taking more rigorous programs of study has increased as well. Of course, one would expect curriculum choice to change over time as the occupational mix of labor demand changes. As we discuss in Section 4, part of the trend is due to changes in state level graduation requirements. It would be interesting to decompose trends in college attendance and major choice over the past 40 years into the contribution of changes in high school curriculum and the contribution of changes in the link between high school curriculum and major choice.

We are not aware of any study that has estimated a structural model of high school curriculum choice along the lines sketched in the previous section. Zietz and Joshi (2005) use the NLSY (1997) to estimate a two-period model of leisure maximization, subject to minimum consumption constraints. They find that "academic aptitude, pre-high school academic performance, and lifetime consumption goals as driven by peer pressure and family background are by far the most important determinants of program choice." Meer (2007), using the NELS88 data, finds that the principle of comparative advantage is at play when students choose between academic and vocational high school curricula. In the remainder of this section, we briefly summarize some of the descriptive evidence on the determinants of curriculum.

There is a substantial literature on the role of gender, race/ethnicity, and socio-economic status in determining high school curriculum, which we touch on briefly here. Historically, girls tended to take less math and science than boys, despite equal (or greater) opportunities or prior achievement (Oakes (1990), Catsambis (1994), Ayalon (1995)). Girls tend to have less positive attitudes toward or fewer aspirations for careers in math or science; they are less interested in math and less confident about their mathematics 
abilities (Dick \& Rallis (1991)). However, Goldin et al (2006) report that among graduating seniors the male/female ratio of mean number of high school courses in math, science courses, and chemistry declined from between 1.3 and 1.4 in 1957 to between 0.9 and 1.0 in 2000. In physics, the male/female ratio declined from 3.1 to 1.21 .

Students from high SES backgrounds tend to be streamed into more academic tracks; this can be explained by a variety of factors including higher intrinsic ability (cognitive or non-cognitive), choice of school and neighborhood, better preparation in primary school, peer effects, or parental lobbying (Vanfossen, Jones \& Spade (1987)). Interestingly, African-American and Latino students have positive attitudes toward math, despite low achievement (Catsambis (1994)). That said, minorities enroll in math-intensive courses at lower rates than whites; however, this is mostly explained by SES and prior achievement (as measured, for example, by GPA) (Ferguson (2009)).

Recent reports discussing student course taking and achievement with emphasis science, engineering, technology and math, include President's Council on Science and Technology (2011).

\section{School-level influences}

School policies, particularly course requirements, scope of offerings, and tracking guidelines, are an important influence on curriculum choice. These policies are in turn shaped in part by state and school district regulations, as we document below. A substantial fraction of the variance in curriculum choice is across high schools (see note 9 ).

To the extent that school behavior can be taken as independent of the unobserved characteristics of the students that attend the school, such variation can be (and has been) used to identify the effects of particular high school curricula. In practice, however, school choice and cross school competition and specialization (attracting particular parts of the student market) will undermine the credibility of such a strategy. In Section 3, we discuss three studies that use curriculum reforms as a source of exogenous variation.

Peers, teachers and facilities (e.g., availability of science labs or a theater) may also influence curriculum choice, but attempts to identify the causal effect of these factors are subject to the same endogeneity problem.

\section{References}

[1] Ayalon H. 1995. Math as a gatekeeper: ethnic and gender inequality in course taking of the sciences in Israel. Amer. J. Educ. 104(1): 34-56 
[2] Catsambis S. 1994. The path to math: gender and racial-ethnic differences in mathematics participation from middle school to high school. Soc. Educ. 67(3):199-215

[3] Dick TP, Rallis SF. 1991. Factors and influences on high school students' career choices. J. Research Math. Educ. 22(4):281-92

[4] Ferguson, RF. 2009. Do racially disparate advanced course enrollments cause opportunity-tolearn gaps in US high schools? Working paper, Harvard.

[5] Ingels SJ, Dalton BW, LoGerfo L. 2008. Trends among high school seniors, 1972-2004 (NCES 2008-320). Washington, DC: US Department of Education, National Center for Education Statistics

[6] Meer J. 2007. Evidence on the returns to secondary vocational education. Econ. Educ. Rev. 26(5):559-573

[7] Nord C, Roey S, Perkins R, Lyons M, Lemanski N, Tamir Y, Brown J, Schuknecht J, Herrold K. 2011. America's high school graduates: results from the 2009 NAEP high school transcript study (NCES 2011-462). Washington, DC: US Department of Education, National Center for Education Statistics

[8] Oakes J. 1990. Multiplying inequalities: the effects of race, social class, and tracking on opportunities to learn mathematics and science. RAND.

[9] Vanfossen BE, Jones JD, Spade JZ. 1987. Curriculum tracking and status maintenance. Soc. Educ. 60(2):104-22

[10] Zietz J, Joshi P. 2005. Academic choice behavior of high school students: economic rationale and empirical evidence. Econ. Educ. Rev. 24(3):297-308 


\section{Supplementary Tables and Figures}


Supplementary Table 1: Trends in high school course-taking

\begin{tabular}{lrr}
\hline \hline & 1990 & 2005 \\
\hline Credits earned, total & 23.6 & 27.2 \\
Core academic, total & 13.7 & 16.0 \\
Core science & 2.8 & 3.5 \\
Core math & 3.2 & 3.9 \\
Core social science & 3.5 & 4.2 \\
Core English & 4.1 & 4.4 \\
Percentage taking curricula that are: & & \\
Rigorous & 5 & 13 \\
Midlevel & 26 & 46 \\
Standard & 9 & 16 \\
Below standard & 60 & 25 \\
Percentage taking STEM courses: & & \\
Algebra II & 53 & 76 \\
Calculus & 7 & 17 \\
Advanced biology & 28 & 45 \\
Chemistry & 45 & 70 \\
Physics & 24 & 39 \\
\hline From 2011 NAEP report. All differences are significant \\
at 5\%.
\end{tabular}




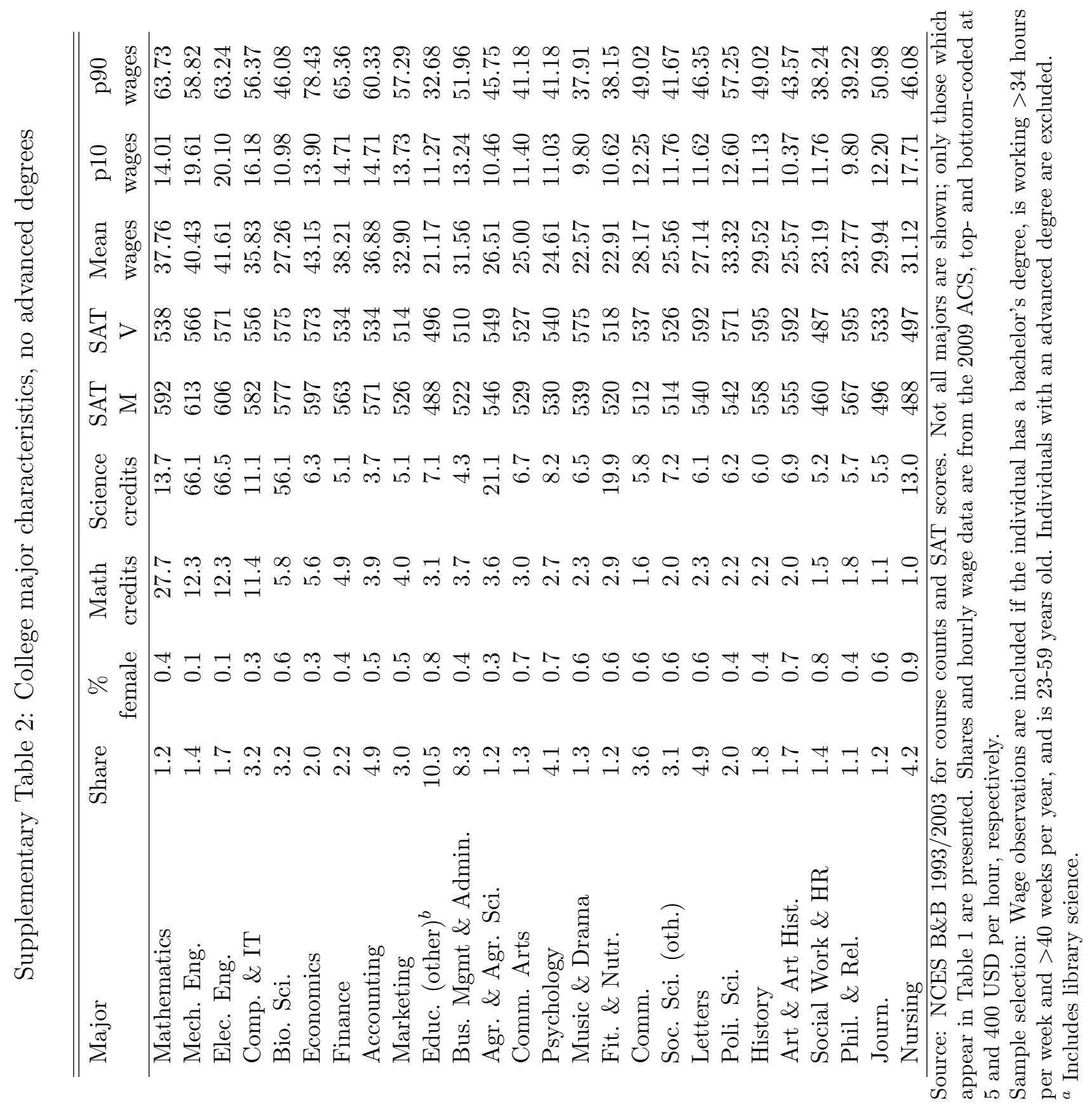


Supplementary Table 3: Effects of college major on log wages by gender, with and without occupation controls - all control variables and major coefficients reported

\begin{tabular}{|c|c|c|c|c|}
\hline \multirow[t]{2}{*}{ Major } & \multicolumn{2}{|c|}{ Major dummies only } & \multicolumn{2}{|c|}{ With occupation controls } \\
\hline & Female & Male & Female & Male \\
\hline PhD & $0.290 * * *$ & $0.220^{* * *}$ & $0.296^{* * *}$ & $0.264^{* * *}$ \\
\hline Masters & $0.204^{* * *}$ & $0.173^{* * *}$ & $0.181^{* * *}$ & $0.139 * * *$ \\
\hline Professional degree & $0.441^{* * *}$ & $0.497^{* * *}$ & $0.254^{* * *}$ & $0.259 * * *$ \\
\hline Potential experience & $0.083^{* * *}$ & $0.097^{* * *}$ & $0.066^{* * *}$ & $0.083^{* * *}$ \\
\hline Potential experience $^{2}$ & $-0.003^{* * *}$ & $-0.003^{* * *}$ & $-0.002^{* * *}$ & $-0.002^{* * *}$ \\
\hline Potential experience $^{3}$ & $0.000 * * *$ & $0.000 * * *$ & $0.000 * * *$ & $0.000 * * *$ \\
\hline Black, non-hispanic & $-0.084^{* * *}$ & $-0.215^{* * *}$ & $-0.052^{* * *}$ & $-0.137 * * *$ \\
\hline Native American, non-hispanic & $-0.163^{* * *}$ & $-0.171^{* * *}$ & $-0.132 * * *$ & $-0.139 * * *$ \\
\hline Asian, non-hispanic & $-0.022^{* *}$ & $-0.099 * * *$ & -0.000 & $-0.076^{* * *}$ \\
\hline Pacific Islander, non-hispanic & $-0.220^{* *}$ & -0.159 & -0.114 & -0.089 \\
\hline Mixed raced, non-hispanic & $-0.044^{* *}$ & $-0.085^{* * *}$ & $-0.038^{* *}$ & $-0.059 * * *$ \\
\hline Any race hispanic & $-0.088^{* * *}$ & $-0.205^{* * *}$ & $-0.037 * * *$ & $-0.130 * * *$ \\
\hline General Agriculture & -0.043 & -0.059 & $-0.094^{*}$ & -0.068 \\
\hline Agriculture Production And Management & 0.011 & 0.047 & $-0.101^{*}$ & 0.034 \\
\hline Agricultural Economics & 0.074 & $0.150^{* *}$ & -0.010 & 0.027 \\
\hline Animal Sciences & $-0.079^{*}$ & $-0.078^{*}$ & $-0.074^{*}$ & -0.060 \\
\hline Food Science & $0.255^{* * *}$ & $0.236^{*}$ & 0.110 & 0.120 \\
\hline Plant Science And Agronomy & -0.027 & 0.026 & -0.041 & 0.029 \\
\hline Soil Science & -0.292 & 0.127 & -0.280 & 0.103 \\
\hline Miscellaneous Agriculture & 0.053 & 0.154 & -0.042 & 0.079 \\
\hline Environmental Science & $0.095^{* *}$ & $0.162^{* * *}$ & -0.032 & 0.036 \\
\hline Forestry & $0.250^{* * *}$ & $0.157^{* * *}$ & $0.162^{* * *}$ & 0.048 \\
\hline Natural Resources Management & 0.047 & $0.112^{* * *}$ & -0.038 & 0.000 \\
\hline Architecture & $0.238 * * *$ & $0.272^{* * *}$ & $0.067^{*}$ & $0.086^{* * *}$ \\
\hline Area Ethnic And Civilization Studies & $0.155^{* * *}$ & $0.247^{* * *}$ & $0.063^{*}$ & $0.122^{* *}$ \\
\hline Communications & $0.202^{* * *}$ & $0.207^{* * *}$ & $0.063^{* * *}$ & $0.058^{* *}$ \\
\hline Journalism & $0.174^{* * *}$ & $0.183^{* * *}$ & 0.029 & 0.033 \\
\hline Mass Media & $0.112^{* * *}$ & $0.102^{* * *}$ & 0.013 & -0.011 \\
\hline Advertising And Public Relations & $0.181^{* * *}$ & $0.228 * * *$ & 0.018 & 0.057 \\
\hline Communication Technologies & $0.188^{* * *}$ & $0.165^{* * *}$ & 0.039 & 0.042 \\
\hline Computer And Information Systems & $0.295^{* * *}$ & $0.421^{* * *}$ & $0.072^{* *}$ & $0.160^{* * *}$ \\
\hline Computer Programming And Data Processi & -0.052 & $0.229 * * *$ & -0.091 & 0.043 \\
\hline Computer Science & $0.441^{* * *}$ & $0.531^{* * *}$ & $0.161^{* * *}$ & $0.242^{* * *}$ \\
\hline Information Sciences & $0.410^{* * *}$ & $0.421^{* * *}$ & $0.167^{* * *}$ & $0.164^{* * *}$ \\
\hline Computer Administration Management And & $0.290 * * *$ & $0.357^{* * *}$ & 0.076 & $0.134^{* *}$ \\
\hline Computer Networking And Telecommunicat & $0.174^{* *}$ & $0.258 * * *$ & 0.036 & 0.074 \\
\hline
\end{tabular}




\begin{tabular}{|c|c|c|c|c|}
\hline \multirow[t]{2}{*}{ Major } & \multicolumn{2}{|c|}{ Major dummies only } & \multicolumn{2}{|c|}{ With occupation controls } \\
\hline & Female & Male & Female & Male \\
\hline Cosmetology Services And Culinary Arts & $-0.163^{*}$ & -0.024 & -0.003 & $0.165^{*}$ \\
\hline Educational Administration And Supervi & $0.106^{* *}$ & 0.069 & 0.072 & -0.011 \\
\hline School Student Counseling & -0.006 & 0.065 & 0.018 & 0.122 \\
\hline Elementary Education & $-0.024^{*}$ & -0.009 & -0.015 & 0.009 \\
\hline Mathematics Teacher Education & $0.051^{*}$ & 0.006 & 0.020 & 0.015 \\
\hline Physical And Health Education Teaching & $0.059 * *$ & -0.002 & $0.046^{*}$ & -0.002 \\
\hline Early Childhood Education & $-0.057 * * *$ & -0.230 & -0.015 & -0.164 \\
\hline Science And Computer Teacher Education & -0.017 & 0.018 & -0.015 & 0.053 \\
\hline Secondary Teacher Education & 0.031 & 0.010 & 0.010 & 0.013 \\
\hline Special Needs Education & $0.081^{* * *}$ & $0.105^{* *}$ & $0.067 * * *$ & $0.102^{* *}$ \\
\hline Social Science Or History Teacher Educ & 0.013 & -0.014 & -0.001 & -0.016 \\
\hline Teacher Education: Multiple Levels & -0.012 & 0.003 & -0.014 & 0.021 \\
\hline Language And Drama Education & 0.031 & 0.013 & 0.016 & 0.035 \\
\hline Art And Music Education & -0.004 & -0.040 & -0.007 & 0.000 \\
\hline Miscellaneous Education & $0.043^{*}$ & 0.052 & 0.015 & -0.011 \\
\hline General Engineering & $0.417^{* * *}$ & $0.392^{* * *}$ & $0.170 * * *$ & $0.169 * * *$ \\
\hline Aerospace Engineering & $0.616^{* * *}$ & $0.548^{* * *}$ & $0.274^{* * *}$ & $0.272^{* * *}$ \\
\hline Biological Engineering & $0.224^{* *}$ & $0.135^{*}$ & 0.053 & 0.025 \\
\hline Architectural Engineering & $0.542^{* * *}$ & $0.357^{* * *}$ & $0.262^{* *}$ & $0.171^{* *}$ \\
\hline Biomedical Engineering & $0.468 * * *$ & $0.472^{* * *}$ & $0.203^{* *}$ & $0.171^{* *}$ \\
\hline Chemical Engineering & $0.526 * * *$ & $0.614^{* * *}$ & $0.252^{* * *}$ & $0.346^{* * *}$ \\
\hline Civil Engineering & $0.406^{* * *}$ & $0.482^{* * *}$ & $0.138 * * *$ & $0.240 * * *$ \\
\hline Computer Engineering & $0.562^{* * *}$ & $0.606^{* * *}$ & $0.227^{* * *}$ & $0.293^{* * *}$ \\
\hline Electrical Engineering & $0.556^{* * *}$ & $0.561^{* * *}$ & $0.258 * * *$ & $0.293^{* * *}$ \\
\hline Engineering Mechanics Physics And Scie & $0.715^{* * *}$ & $0.429^{* * *}$ & $0.379 * *$ & $0.235^{* * *}$ \\
\hline Environmental Engineering & $0.400 * * *$ & $0.530 * * *$ & $0.166^{*}$ & $0.267^{* * *}$ \\
\hline Geological And Geophysical Engineering & 0.342 & $0.639^{* * *}$ & 0.063 & $0.385^{* * *}$ \\
\hline Industrial And Manufacturing Engineeri & $0.483^{* * *}$ & $0.469^{* * *}$ & $0.221^{* * *}$ & $0.227 * * *$ \\
\hline Materials Engineering And Materials Sc & $0.341^{* *}$ & $0.429^{* * *}$ & 0.064 & $0.194^{* * *}$ \\
\hline Mechanical Engineering & $0.554^{* * *}$ & $0.524^{* * *}$ & $0.265 * * *$ & $0.264^{* * *}$ \\
\hline Metallurgical Engineering & $0.374^{*}$ & $0.452^{* * *}$ & 0.155 & $0.209 * * *$ \\
\hline Mining And Mineral Engineering & $0.771^{*}$ & $0.412^{* * *}$ & 0.590 & $0.215^{* *}$ \\
\hline Naval Architecture And Marine Engineer & $0.530^{* *}$ & $0.360^{* * *}$ & $0.246^{*}$ & 0.147 \\
\hline Nuclear Engineering & $0.600 * *$ & $0.651^{* * *}$ & 0.364 & $0.406^{* * *}$ \\
\hline Petroleum Engineering & $0.682^{* * *}$ & $0.869 * * *$ & $0.332^{*}$ & $0.590 * * *$ \\
\hline Miscellaneous Engineering & $0.260 * * *$ & $0.394^{* * *}$ & 0.129 & $0.206^{* * *}$ \\
\hline Engineering Technologies & 0.141 & $0.345^{* * *}$ & 0.010 & $0.143^{* * *}$ \\
\hline Engineering And Industrial Management & $0.298 * *$ & $0.374^{* * *}$ & 0.111 & $0.135^{* *}$ \\
\hline Electrical Engineering Technology & 0.150 & $0.315^{* * *}$ & -0.075 & $0.140 * * *$ \\
\hline Industrial Production Technologies & $0.282^{* * *}$ & $0.261^{* * *}$ & $0.146^{*}$ & $0.087^{* *}$ \\
\hline Mechanical Engineering Related Technol & $0.481^{* * *}$ & $0.262^{* * *}$ & $0.186^{*}$ & $0.107^{* *}$ \\
\hline
\end{tabular}




\begin{tabular}{|c|c|c|c|c|}
\hline \multirow[t]{2}{*}{ Major } & \multicolumn{2}{|c|}{ Major dummies only } & \multicolumn{2}{|c|}{ With occupation controls } \\
\hline & Female & Male & Female & Male \\
\hline Miscellaneous Engineering Technologies & $0.176^{*}$ & $0.327^{* * *}$ & 0.041 & $0.121^{* * *}$ \\
\hline Linguistics And Comparative Language A & $0.080^{*}$ & $0.172^{*}$ & 0.001 & 0.047 \\
\hline French German Latin And Other Common F & $0.128^{* * *}$ & $0.164^{* * *}$ & $0.066^{* * *}$ & $0.070^{*}$ \\
\hline Other Foreign Languages & 0.081 & $0.117^{*}$ & 0.017 & 0.047 \\
\hline Family And Consumer Sciences & 0.020 & $0.203^{* * *}$ & -0.002 & $0.102^{*}$ \\
\hline Court Reporting & $0.289^{*}$ & -0.013 & 0.067 & -0.014 \\
\hline Pre-Law And Legal Studies & $0.139^{* * *}$ & $0.234^{* * *}$ & 0.017 & $0.117^{*}$ \\
\hline English Language And Literature & $0.107^{* * *}$ & $0.152^{* * *}$ & $0.026^{*}$ & $0.063^{* * *}$ \\
\hline Composition And Speech & $0.090^{*}$ & $0.141^{* *}$ & 0.002 & $0.090^{*}$ \\
\hline Liberal Arts & $0.073^{* * *}$ & $0.154^{* * *}$ & 0.021 & $0.055^{*}$ \\
\hline Humanities & $0.113^{*}$ & 0.113 & 0.044 & 0.004 \\
\hline Library Science & -0.046 & 0.110 & -0.036 & 0.073 \\
\hline Biology & $0.196^{* * *}$ & $0.302^{* * *}$ & $0.068 * * *$ & $0.114^{* * *}$ \\
\hline Biochemical Sciences & $0.262^{* * *}$ & $0.308 * * *$ & $0.096^{* *}$ & $0.111^{* *}$ \\
\hline Botany & -0.012 & 0.008 & -0.062 & -0.007 \\
\hline Molecular Biology & $0.196 * * *$ & $0.260 * * *$ & 0.080 & $0.112^{*}$ \\
\hline Ecology & 0.050 & 0.068 & -0.008 & 0.012 \\
\hline Genetics & $0.196^{* *}$ & 0.178 & 0.080 & 0.025 \\
\hline Microbiology & $0.185^{* * *}$ & $0.228 * * *$ & 0.063 & 0.071 \\
\hline Pharmacology & $0.387^{* *}$ & 0.168 & 0.135 & 0.022 \\
\hline Physiology & $0.157^{* * *}$ & $0.193^{* * *}$ & 0.016 & 0.077 \\
\hline Zoology & 0.088 & $0.328 * * *$ & -0.005 & $0.153^{* * *}$ \\
\hline Miscellaneous Biology & $0.154^{* *}$ & $0.189^{* * *}$ & 0.075 & 0.057 \\
\hline Mathematics & $0.288^{* * *}$ & $0.426^{* * *}$ & $0.143^{* * *}$ & $0.224^{* * *}$ \\
\hline Applied Mathematics & $0.537^{* * *}$ & $0.641^{* * *}$ & $0.286^{* * *}$ & $0.375^{* * *}$ \\
\hline Statistics And Decision Science & $0.473^{* * *}$ & $0.523^{* * *}$ & $0.228 * * *$ & $0.206^{* * *}$ \\
\hline Military Technologies & $0.670 * * *$ & 0.280 & $0.761^{* * *}$ & 0.099 \\
\hline Intercultural And International Studie & $0.119^{* *}$ & $0.192^{* * *}$ & 0.019 & 0.061 \\
\hline Nutrition Sciences & $0.144^{* * *}$ & $0.402^{* * *}$ & $0.081^{*}$ & $0.232^{*}$ \\
\hline Neuroscience & 0.088 & 0.160 & -0.094 & -0.032 \\
\hline Mathematics And Computer Science & $0.722^{* *}$ & $0.638 * * *$ & $0.444^{*}$ & $0.335^{* * *}$ \\
\hline Cognitive Science And Biopsychology & 0.164 & $0.367^{* *}$ & 0.022 & 0.137 \\
\hline Interdisciplinary Social Sciences & $0.082^{*}$ & $0.195^{* * *}$ & 0.019 & 0.081 \\
\hline Multi-Disciplinary Or General Science & $0.116^{* * *}$ & $0.282^{* * *}$ & 0.015 & $0.110^{* * *}$ \\
\hline Physical Fitness Parks Recreation And & 0.018 & $0.045^{*}$ & -0.034 & 0.005 \\
\hline Philosophy And Religious Studies & $0.086^{*}$ & -0.003 & 0.028 & -0.004 \\
\hline Theology And Religious Vocations & $-0.242^{* * *}$ & $-0.304^{* * *}$ & $-0.172^{* * *}$ & $-0.142^{* * *}$ \\
\hline Physical Sciences & -0.085 & 0.130 & $-0.163^{*}$ & 0.016 \\
\hline Astronomy And Astrophysics & $0.438^{* *}$ & $0.339 * *$ & $0.378^{*}$ & $0.212^{* *}$ \\
\hline Atmospheric Sciences And Meteorology & 0.196 & $0.335^{* * *}$ & 0.097 & $0.152^{* *}$ \\
\hline Chemistry & $0.250 * * *$ & $0.366^{* * *}$ & $0.101^{* * *}$ & $0.193^{* * *}$ \\
\hline
\end{tabular}




\begin{tabular}{|c|c|c|c|c|}
\hline \multirow[t]{2}{*}{ Major } & \multicolumn{2}{|c|}{ Major dummies only } & \multicolumn{2}{|c|}{ With occupation controls } \\
\hline & Female & Male & Female & Male \\
\hline Geology And Earth Science & $0.162^{* * *}$ & $0.261^{* * *}$ & 0.018 & $0.117^{* * *}$ \\
\hline Geosciences & $0.332^{*}$ & $0.422^{* * *}$ & 0.095 & $0.213^{* *}$ \\
\hline Oceanography & 0.025 & $0.244^{* * *}$ & -0.037 & 0.086 \\
\hline Physic & $0.292^{* * *}$ & $0.383^{* * *}$ & $0.113^{* * *}$ & $0.187^{* * *}$ \\
\hline Nuclear, Industrial Radiology, And Bio & 0.155 & $0.276^{* * *}$ & 0.000 & 0.112 \\
\hline Psychology & $0.076^{* * *}$ & $0.157^{* * *}$ & 0.019 & $0.051^{* *}$ \\
\hline Educational Psychology & -0.015 & -0.098 & -0.026 & -0.115 \\
\hline Clinical Psychology & $0.149^{* *}$ & 0.119 & 0.109 & 0.087 \\
\hline Counseling Psychology & $-0.095^{* *}$ & -0.102 & $-0.100^{* *}$ & -0.111 \\
\hline Industrial And Organizational Psycholo & $0.176^{* *}$ & $0.466^{* * *}$ & 0.046 & $0.247^{* * *}$ \\
\hline Social Psychology & 0.054 & 0.129 & -0.007 & -0.028 \\
\hline Miscellaneous Psychology & 0.060 & $0.199 * *$ & -0.004 & $0.149^{*}$ \\
\hline Criminal Justice And Fire Protection & $0.076^{* * *}$ & $0.226^{* * *}$ & -0.013 & $0.076^{* * *}$ \\
\hline Public Administration & $0.240 * * *$ & $0.292^{* * *}$ & 0.051 & $0.098 * *$ \\
\hline Public Policy & $0.204^{* *}$ & $0.346^{* * *}$ & 0.028 & $0.170^{*}$ \\
\hline Human Services And Community Organizat & $-0.077^{* *}$ & -0.016 & $-0.098 * * *$ & -0.052 \\
\hline Social Work & -0.027 & 0.009 & $-0.034^{*}$ & 0.017 \\
\hline General Social Sciences & $0.055^{*}$ & $0.166^{* * *}$ & 0.017 & $0.099^{* *}$ \\
\hline Economics & $0.400 * * *$ & $0.517 * * *$ & $0.224^{* * *}$ & $0.275^{* * *}$ \\
\hline Anthropology And Archeology & $0.069^{* *}$ & $0.135^{* * *}$ & -0.001 & 0.053 \\
\hline Criminology & $0.123^{* *}$ & $0.191^{* * *}$ & 0.052 & 0.064 \\
\hline Geography & $0.154^{* * *}$ & $0.212^{* * *}$ & 0.004 & $0.085^{* * *}$ \\
\hline International Relations & $0.242^{* * *}$ & $0.398 * * *$ & $0.093^{* *}$ & $0.229^{* * *}$ \\
\hline Political Science And Government & $0.246^{* * *}$ & $0.327^{* * *}$ & $0.112^{* * *}$ & $0.158^{* * *}$ \\
\hline Sociology & $0.077^{* * *}$ & $0.165^{* * *}$ & 0.012 & $0.075^{* * *}$ \\
\hline Miscellaneous Social Sciences & $0.340^{* * *}$ & $0.364^{* * *}$ & $0.164^{* *}$ & $0.213^{* *}$ \\
\hline Construction Services & $0.298^{*}$ & $0.430 * * *$ & 0.121 & $0.225^{* * *}$ \\
\hline Electrical And Mechanic Repairs And Te & $-0.550^{*}$ & $0.145^{*}$ & -0.332 & 0.108 \\
\hline Precision Production And Industrial Ar & $0.122^{*}$ & -0.003 & 0.025 & 0.013 \\
\hline Transportation Sciences And Technologi & $0.292^{* * *}$ & $0.259^{* * *}$ & 0.111 & $0.081^{* *}$ \\
\hline Fine Arts & -0.021 & 0.017 & $-0.067^{* *}$ & -0.035 \\
\hline Drama And Theater Arts & -0.025 & $-0.089^{*}$ & $-0.065^{*}$ & $-0.135 * * *$ \\
\hline Music & $-0.109 * * *$ & -0.034 & $-0.109 * * *$ & -0.038 \\
\hline Visual And Performing Arts & -0.097 & 0.122 & -0.084 & 0.028 \\
\hline Commercial Art And Graphic Design & $0.093^{* * *}$ & $0.127 * * *$ & -0.017 & 0.009 \\
\hline Film Video And Photographic Arts & 0.014 & 0.082 & -0.012 & 0.007 \\
\hline Art History And Criticism & $0.132^{* * *}$ & $0.263^{* *}$ & $0.064^{*}$ & 0.149 \\
\hline Studio Arts & -0.020 & $-0.147^{*}$ & -0.031 & $-0.178^{* *}$ \\
\hline General Medical And Health Services & $0.163^{* * *}$ & $0.183^{* * *}$ & 0.032 & $0.105^{*}$ \\
\hline Communication Disorders Sciences And S & $0.144^{* * *}$ & $0.294^{* * *}$ & $0.049^{*}$ & $0.138^{*}$ \\
\hline Health And Medical Administrative Serv & $0.197 * * *$ & $0.242^{* * *}$ & 0.058 & 0.058 \\
\hline
\end{tabular}




\begin{tabular}{|c|c|c|c|c|}
\hline \multirow[t]{2}{*}{ Major } & \multicolumn{2}{|c|}{ Major dummies only } & \multicolumn{2}{|c|}{ With occupation controls } \\
\hline & Female & Male & Female & Male \\
\hline Medical Assisting Services & $0.338^{* * *}$ & $0.315^{* * *}$ & $0.177^{* * *}$ & $0.152^{*}$ \\
\hline Medical Technologies Technicians & $0.252^{* * *}$ & $0.360 * * *$ & $0.137^{* * *}$ & $0.266^{* * *}$ \\
\hline Health And Medical Preparatory Program & $0.481^{* * *}$ & $0.496^{* * *}$ & $0.306^{* * *}$ & $0.190^{* *}$ \\
\hline Nursing & $0.391^{* * *}$ & $0.408 * * *$ & $0.172^{* * *}$ & $0.243^{* * *}$ \\
\hline Pharmacy Pharmaceutical Sciences And A & $0.641^{* * *}$ & $0.626^{* * *}$ & $0.253^{* * *}$ & $0.406^{* * *}$ \\
\hline Treatment Therapy Professions & $0.208 * * *$ & $0.220 * * *$ & $0.101^{* * *}$ & $0.095^{* *}$ \\
\hline Community And Public Health & $0.151^{* * *}$ & $0.226^{* * *}$ & 0.030 & 0.076 \\
\hline Miscellaneous Health Medical Professio & -0.042 & 0.083 & -0.035 & 0.078 \\
\hline General Business & $0.218^{* * *}$ & $0.339 * * *$ & $0.077^{* * *}$ & $0.142^{* * *}$ \\
\hline Accounting & $0.310 * * *$ & $0.431^{* * *}$ & $0.143^{* * *}$ & $0.199^{* * *}$ \\
\hline Actuarial Science & $0.632^{* * *}$ & $0.764^{* * *}$ & 0.160 & $0.337^{* * *}$ \\
\hline Business Management And Administration & $0.199 * * *$ & $0.292^{* * *}$ & $0.054^{* * *}$ & $0.104^{* * *}$ \\
\hline Operations Logistics And E-Commerce & $0.350 * * *$ & $0.403^{* * *}$ & $0.169^{* * *}$ & $0.181^{* * *}$ \\
\hline Business Economics & $0.432^{* * *}$ & $0.458^{* * *}$ & $0.273^{* * *}$ & $0.204^{* * *}$ \\
\hline Marketing And Marketing Research & $0.256^{* * *}$ & $0.356^{* * *}$ & $0.089^{* * *}$ & $0.150^{* * *}$ \\
\hline Finance & $0.342^{* * *}$ & $0.518^{* * *}$ & $0.151^{* * *}$ & $0.243^{* * *}$ \\
\hline Human Resources And Personnel Manageme & $0.203^{* * *}$ & $0.258^{* * *}$ & 0.037 & $0.064^{*}$ \\
\hline International Business & $0.284^{* * *}$ & $0.398 * * *$ & $0.090 * *$ & $0.149^{* * *}$ \\
\hline Hospitality Management & $0.093^{* *}$ & $0.095^{* *}$ & 0.049 & 0.060 \\
\hline Management Information Systems And Sta & $0.406^{* * *}$ & $0.485^{* * *}$ & $0.152^{* * *}$ & $0.223^{* * *}$ \\
\hline Miscellaneous Business \& Medical Admin & 0.063 & $0.363^{* * *}$ & -0.037 & $0.192^{* * *}$ \\
\hline History & $0.105^{* * *}$ & $0.167^{* * *}$ & $0.033^{*}$ & $0.064^{* * *}$ \\
\hline United States History & 0.090 & 0.127 & -0.061 & -0.031 \\
\hline Constant & $2.217^{* * *}$ & $2.214^{* * *}$ & $2.292^{* * *}$ & $2.235^{* * *}$ \\
\hline $\mathrm{R}^{2}$ & 0.200 & 0.217 & 0.330 & 0.337 \\
\hline $\mathrm{N}$ & 125794 & 140706 & 124858 & 139493 \\
\hline
\end{tabular}

Notes: ${ }^{* * *} \mathrm{p}<0.01,{ }^{* *} \mathrm{p}<0.05,{ }^{*} \mathrm{p}<0.10$

Bachelor's degrees are 4-digit. Wages are top- and bottom-coded at 5 and 400 USD per hour, respectively. General Education is the excluded category. Occupation controls are 5 -digit; coefficients not shown.

Sample selection: Observations are included if the individual has at least a bachelor's degree, is working $>34$ hours per week and $>40$ weeks per year, and is 23-59 years old. 


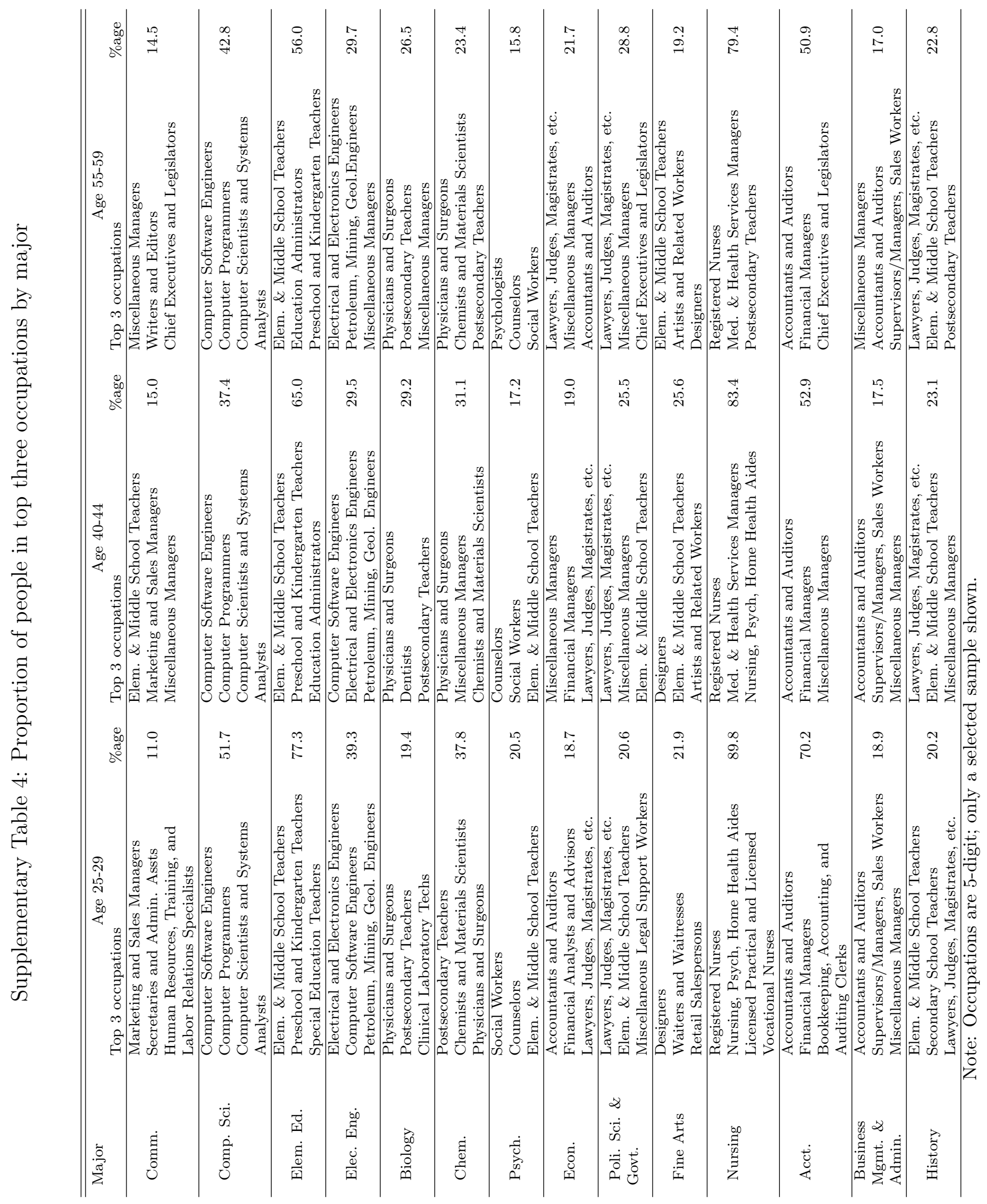




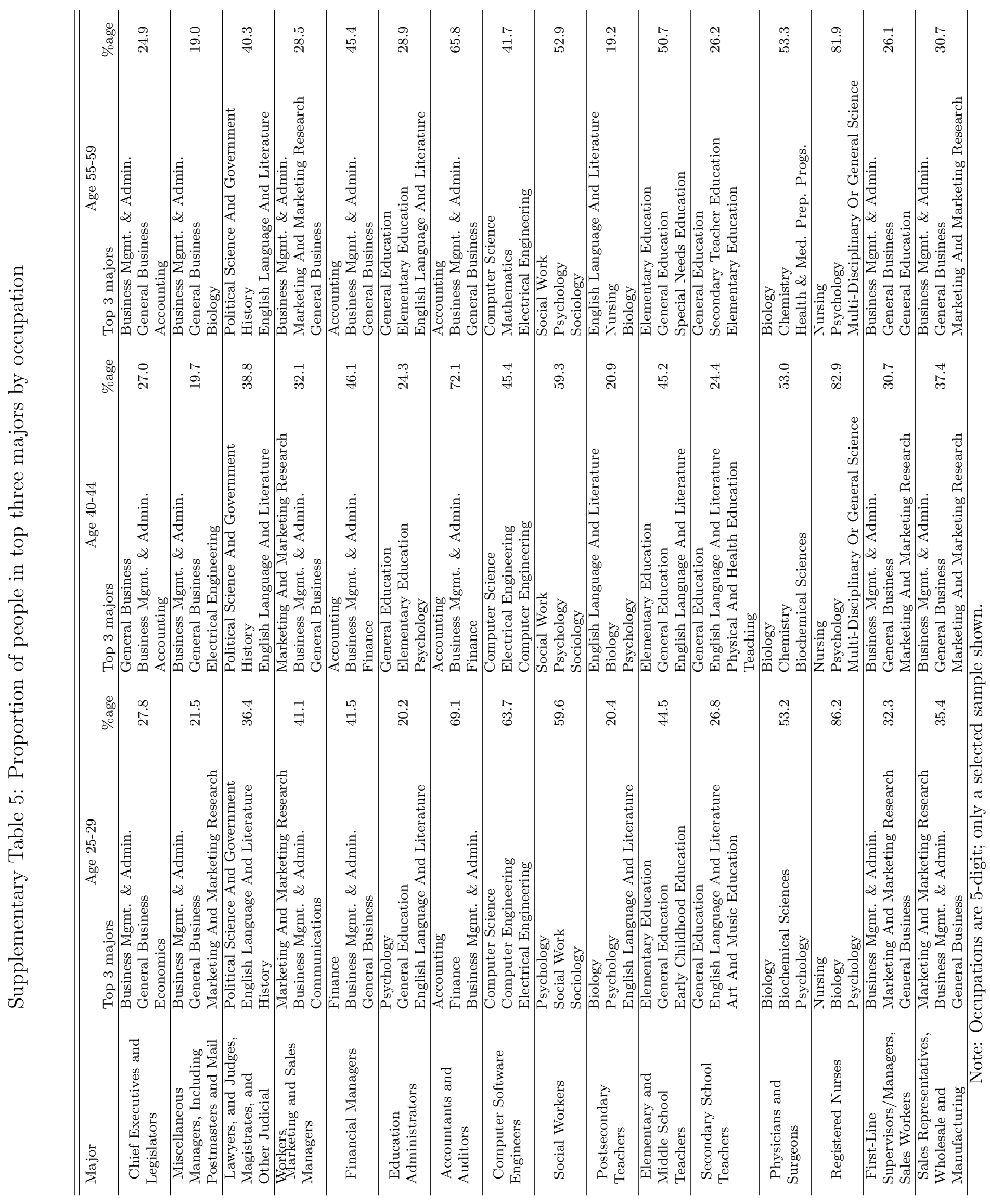


Supplementary Figure 1
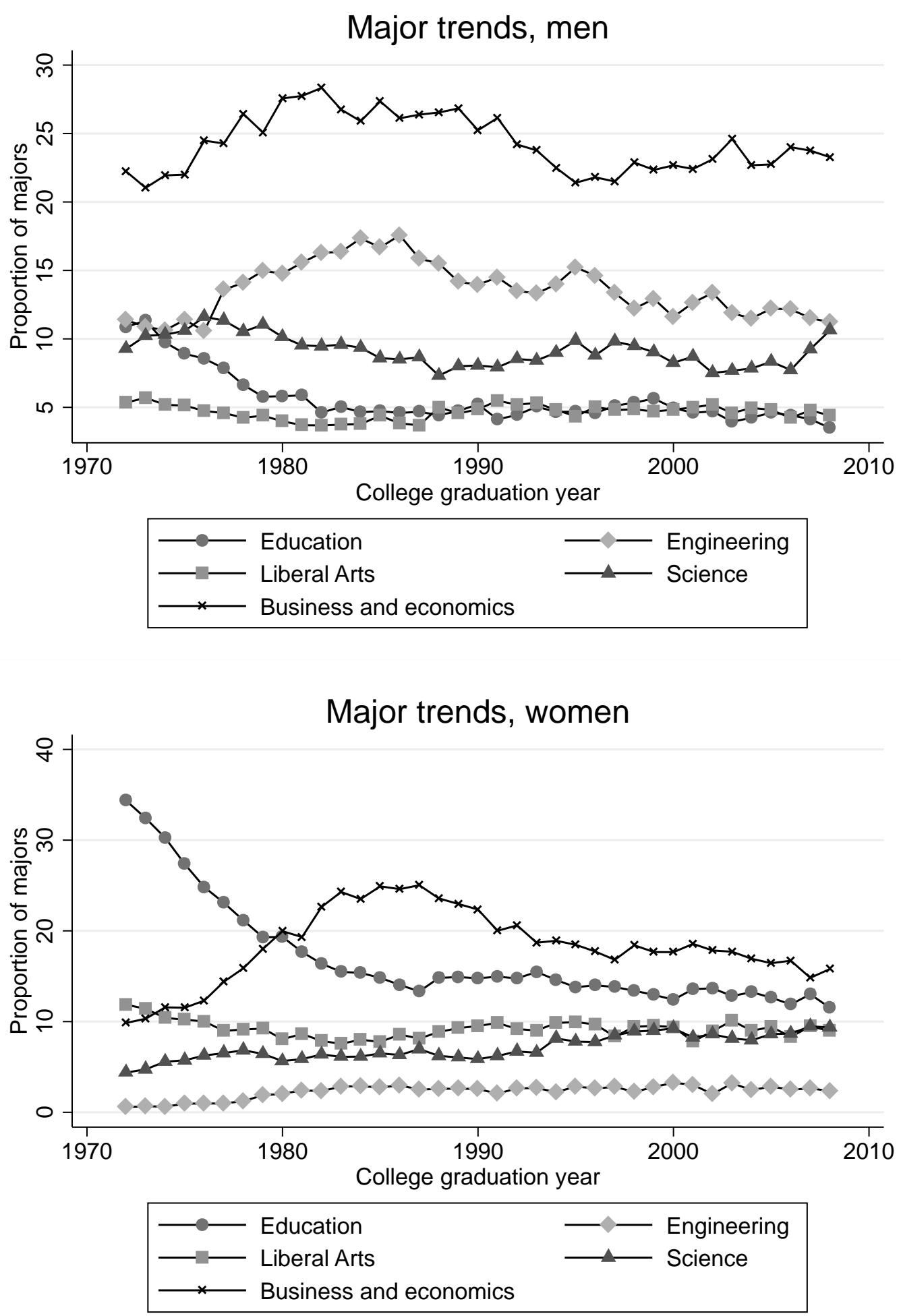

Selected majors only. Data from ACS. 
Supplementary Figure 2
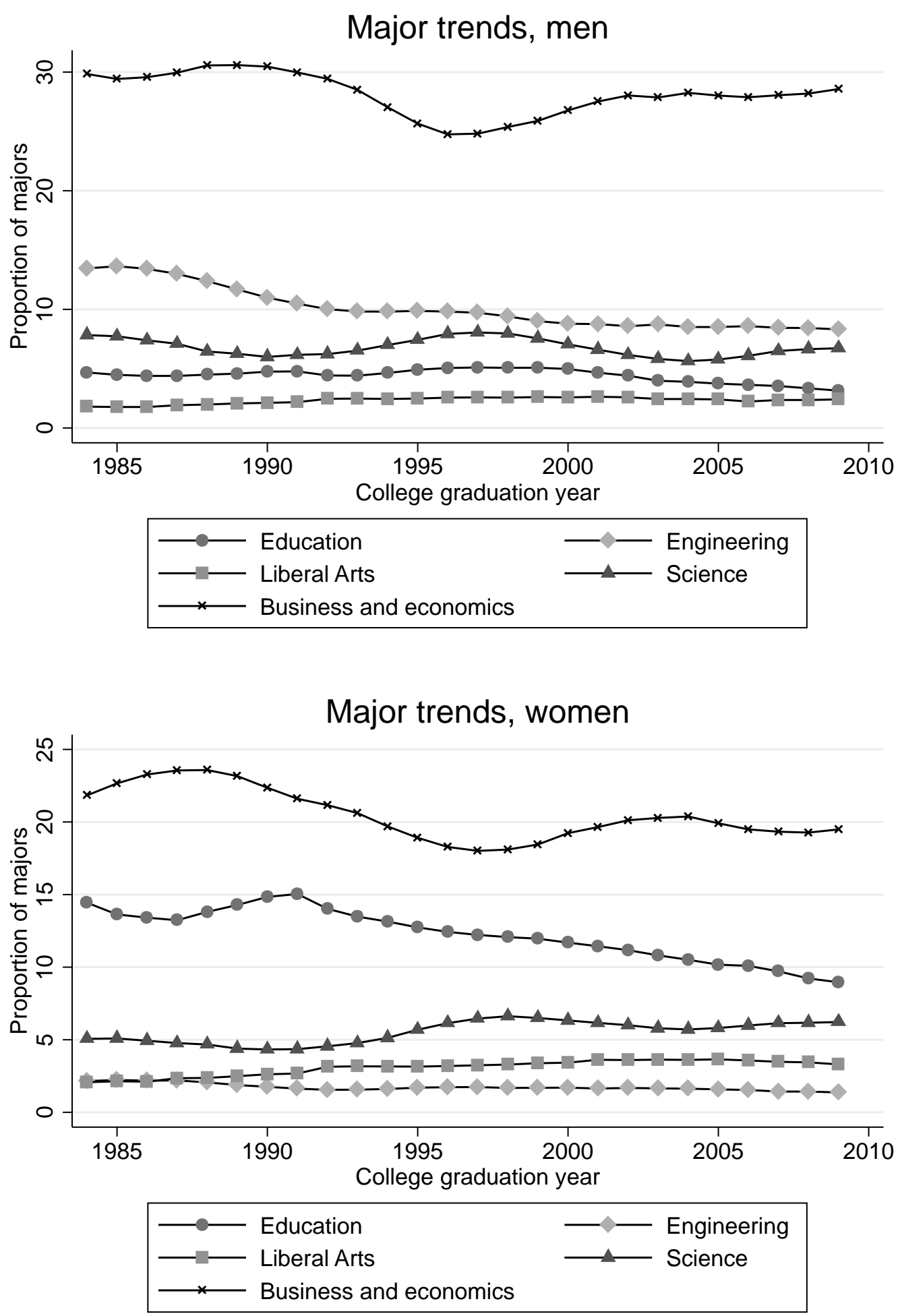

Selected majors only. Data from IPEDS. 